\title{
إمكانات الصورة الشخصية والإفادة منها في إثراء المشغولة النسجية
}

The Potential of the Portrait and its Use in Enriching the Woven Artifact

\author{
م. د/ رباب محمد أحمد حسن الحينى \\ مدرس النسيج بقسم الأثنغال الفنية والتراث الثعبى كلية التربية الفنية ـ جامعة المنيا
}

Dr. Rabab Mohamed Ahmed

Lecturer of Textile at the Department of Artistic Crafts and Heritage -Faculty of Art

Education -Minia University, Egypt.

r.elheny@yahoo.com

فن النسيج اليدوى من ألقدث: الفنون الني مارسها الإنسان وتطورت بنطوره عبر العصور، مما أوجد لدينا تراثاً متتوعاً ثرياً يمثل أغلب ما نسجه الإنسان، فهو من الفنون التي تنطوى على جانب كبير من الإبداع والابتكار و التعبير عن المشاعر، كغيره من مجالات الفنون ليؤدي رسالته الجمالية والوظيفية اللازمة لتنمية الذوق العام، فهو يخاطب وجدان و عقل المتلقي على اختلاف فئاته المتخصص و الغير متخصص ليُشتر تجاوباً فعالاً لتفهم هذا المجال و إمكاناته.

و هناك العديد من المحاولات لإثراء الأعمال الفنية النسجية ـ المشغولات النسجية ـ تتوعت ما بين نطوير الأساليب النسجية الوظيفية للحصول على تأثيرات جمالية وملمسيه على سطح المشغولة، وبين الخامات التقليدية والوسائط التشكيلية، وصو لاً إلى الاهتمام بالتصميم. فالتصميم النسجى بمتاز بأنه تصميم بنائى، يُصاغ من خلال تفاعل مجموعه من العوامل الأساسية تجمع بين مقومات

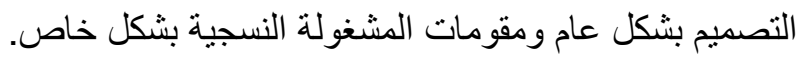

ومن هذا المُنطلق يتخذ هذا البحث الصورة الشخصية ـ البورتريه ـ كمثير تشكيلي غنى بالعديد من الإمكانات التصميمية / البنائية / التشكيلية / و التقنية و التي من خلالها يمكن أن تثرى المشغولة النسجية.

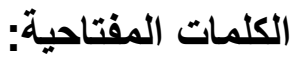
الصورة الثخصية، البورتريه، فن النسيج اليدوى، النسيج المرسم، اللحمات غير الممتدة، المشغولة النسجية.

\begin{abstract}
The art of weaving is one of the oldest arts that has been practiced by man and developed with man's development through the ages, which has created a diverse and rich heritage that represents most of what has been weaved. It is one of the plastic arts that involves a great deal of creativity, innovation, and expression of feelings, like other arts, to perform its aesthetic and functional mission that is necessary for the development of the public taste. Weaving addresses the conscience and mind of the recipient, regardless of their specialization, to produce an effective response so that this field and its potentials can be understood.

There are many attempts to enrich the woven artifacts ranging from the development of applied weaving methods to create aesthetic and tactile effects on the woven artifacts surface, traditional materials and plastic medium, to attention to design.

The weaving design is characterized by its structural design formulated through the interaction of a range of fundamental factors combining the elements of design in general with the components of the woven artifacts in particular.
\end{abstract}


Accordingly, this research takes the portrait as a weaving element/stimulus that is rich in many design, structural, plastic, and technical potentials through which the woven artifacts can be enriched.

\section{Keywords:}

Portrait, weaving, Tapestry, unstretched wefts, woven artifacts.

مقدمة: فن النسيج اليدوى من أقدم الفنون التي مارسها الإنسان وتطورت بتطوره عبر العصور، مما أوجد لدينا تراثاً متتوعاً ثرياً يمثل أغلب ما نسجه الإنسان، فهو من الفنون التشكيلية التي تنطوى على جانب كبير من الإبداع والابتكار و التعبير عن من من المشاعر، كغيره من مجالات الفنون ليؤدي رسالته الجمالية والوظيفية اللازمة لتنمية الذوق العام، فهو يخاطب وجدان و عقل المتلقي على اختلاف فئاته المتخصص و الغير متخصص ليُشمر تجاوباً فعالاً لتفهم هذا المجال و إمكاناته.

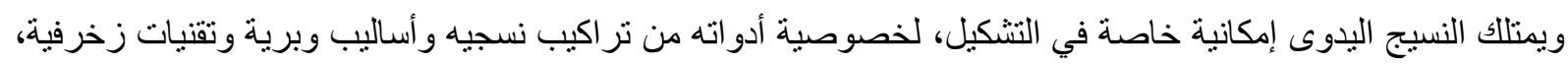

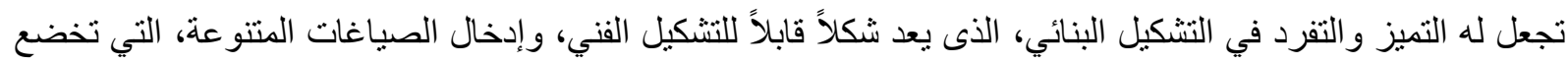

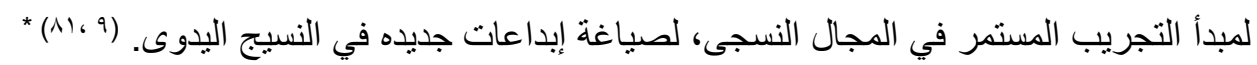
و هناك العديد من المحاولات لإثراء الأعمال الفنية النسجية، تنوعت ما بين تطوير الأساليب النسجية النطبيقية للحصول على تأثير ات جمالية وملمسيه على سطح المشغولة، وبين الخامات التقليدية و الوسائط التشكيلية، وصو لاً إلى الاهتمام بالتصميم. فالتصميم النسجى بمتاز بأنه تصميم بنائى، يُصاغ من خلال تفاعل مجموعه من العوامل الأساسية تجمع بين مقومات

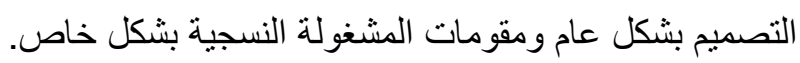
ومن هذا المُنطلق يتخذ هذا البحث الصورة الثخصية ــ البورنريه ــ كمثير تشكيلي غنى بالعديد من الإمكانات التصميمية / البنائية / التشكيلية / و التقنية والتي من خلالها يمكن أن تثرى المشغولة النسجية. هل يمكن الإفادة من بعضة البحث في التساؤل الأتىى: ويتفرع منه التساؤلات الأتية:

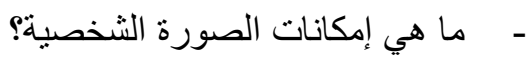
- ما هي المعالجات التصميمية للصورة الثخصية التي تتو افق مع التصميم النسجي الناجح؟ - ما هي الطريقة النسجية الأنسب الني تتوائم مع المعالجات التصميمية للصورة الثخصية في ضوء الإفادة من بعض لهض إمكاناتها لإثر اء المشغولة النسجية؟ المريه

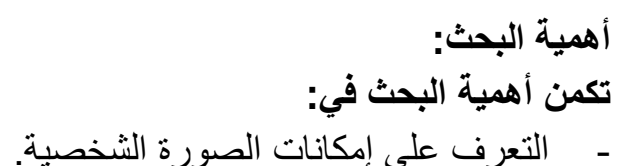
- التعرف على المعالجات التصميمية للصورة الثخصية التي تتو افق مع التصميم النسجي الناجح. - صباغة مشغولة نسجيه معاصرة في ضوء الإفادة من الإمكانات التشكيلية للصورة الثخصية. 


$$
\text { هدف البحث: }
$$

1- الإفادة من بعض إمكانات الصورة الثخصية في إثراء المشغولة النسجية.

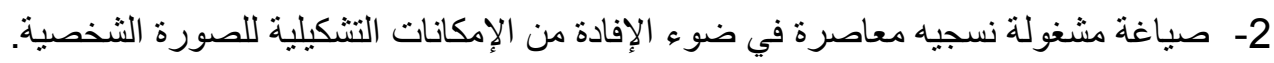

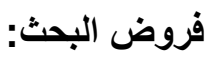

1- يمكن الإفادة من بعض إمكانات الصورة الثخصبة في إثر اء المشغولة النسجية.

2- توجد فروق ذات دلاله إحصائية بين نتائج أفر اد المجموعة الضابطة والتجريبية لصالح المجموعة التجريبية.

حدود البحث: - (الجدود

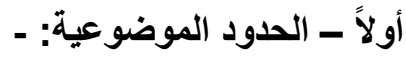

الاستفادة من الإمكانات التشكيلية للصورة التصوية الثخصية.

الاعتماد على الصورة الثخصية الذاتية للطلاب عينة البحث كنوع من التحفيز للإلتزام والمثابرة وإثارة اهتمام

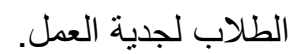

الاستعانة بكاميرات الهاتف المحمول لإلتقاط الصورة الثخصية.

المعالجات التصميمة للصورة الثخصية معتمدة على بعض طرق معالجة الصورة على الهاتف المحمول كمدل

طلابي بسيط غير متعمق في تكنولوجيا التصميم - نربطه علاقة بسيطة بتكنولوجيا التصميم -

الأسلوب النسجى المستخدم: النسيج المرسم حيث اللحمات غير الممتدة في عرض المنسوج.

الخامات المستخدمة: استخدام خيوط الصوف الصناعي متعدد التخانات وخيوط القطن كالحمات والحرير لخيوط

السداء.

النول المستخدم: نول البرواز.

بطاقة تقييم للأعمال النسجية. (من اعداد الباحثة)

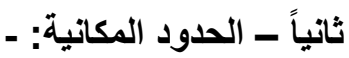
طُبقت التجربة على طلاب الفرقة الثانية، كلية التربية الفنية، جامعة المنيا.

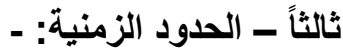

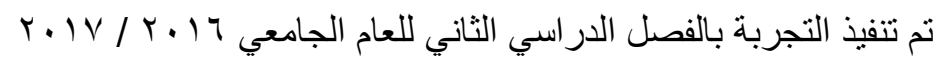
ضمن مقرر دراسات تجريبية في التر اكيب النسجية.

The Portrait الصورة الثخصية

يعرف المعجم الوسيط الصورة بأنها: من الفعل صور، وصورُه جعل له صورة مجسمة وفى التنزيل العزيز (هُوَ الَّنى

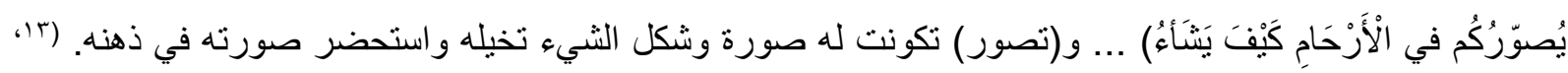

كما يعرف محمود أمهز الصورة الثخصية بأنها " تمثيل لثخص حققي، غالباً ما يقتصر على الوجه في الرسم والتصوير و النحت" (؛، إن)

إمكانات الصورة الشخصية: The Potential of the Portrait نعريف إجر ائي هي المعطيات الجمالية والتشكيلية للصورة الثخصية المتمثلة في الخط و المساحة و اللون ومجموع القيم التشكيلية المحسوسة والملموسة. 
النسيج المرسم: Tapestry يعرفه بلال أحمد بأنه" أحد الأساليب التي استخدمت بوفرة منذ العصور الأولى للفن المصري القديم، فهو مصري النشأة

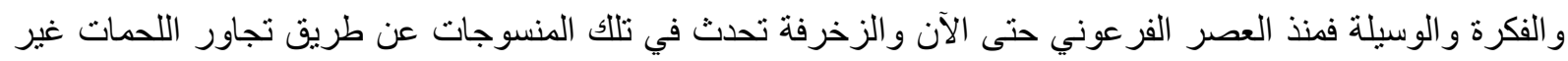
الممندة في عرض المنسوج أحدها تكون الأرضية والأخرى تكون الزخرفة وتعرف هذه المنسوجات في اللغة الأوربية

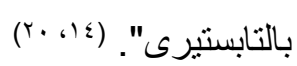
يستخدم البحث المنهج الوصفي التحليلي في دراسة بعض إمكانات الصورة الثخصية وبعض المعالجات التصميمة لها والوقوف على ما يتو افق منها مع التصميم النسجى الناجح، كما يستخدم المنهج شبه التجريبي وذللك في إطار تطبيق التجربة الطلابية.

\section{الإطار النظري للبحث:}

تطور الثكل النسجى في النصف الثاني من القرن العشرين تطور اً في شكله ومضمونه وفلسفة بنائه فكان الاهتمام من ور اء هذا التغيير؛ هو تحقيق قيم فنية مضافه للعمل النسجى الفني، الذي تحول من الصنعة والنمطية الى الابتكار و الإبداع في التشكيل، و التعبير عن تكوينات نسجيه تتميز بالإبداع و الفرادة للعمل اليدوى....ومع التطور الطبيعي الذي حدث في الخامة والتقنية واستخداماتهما عبر العصور، والتقدم الفكري للفنان والنساج كان لابد أن تتحصر النمطية لأداء العمل

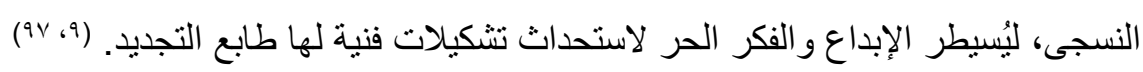

\section{الإمكانات التعبيرية للصورة الشخصية " البورتريه": -}

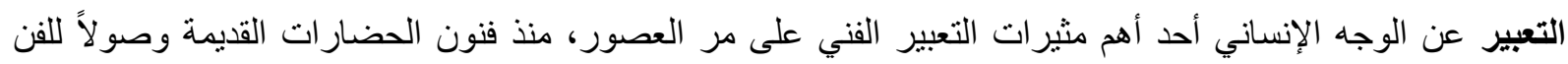
المعاصر ، فقد عبر الكثير من الفنانين عنه بطرق وأساليب ذات أبعاد تشكيلية وتعبيرية وفلسفية متباينة. كما أخذت الصورة الثخصية مساحة عظيمه من إبداعات الفنانين التي تنوعت بين نحت وتصوير وجر افيك وغير ونير ها .....، وذللك على مر العصور وخلال الحقب المتلاحقة كان استخدامها دينياً هو السائد، ولكن مع مرور الوقت انسلخت تئن تدريجياً

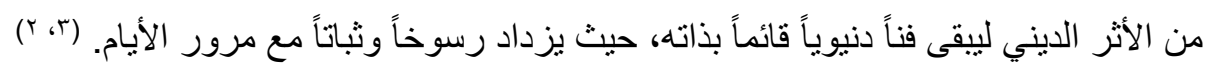
و" يتميز فن البورتريه بمر ادفة التعبير ات المصاحبة للشخصية ، فقد تقدم رسم البورتريه إلى مجلات من الرقى و البراعة

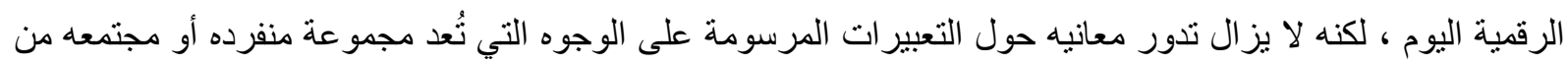
العو اطف ، و على الفنان المبدع الخوض في عدد لا حصر له من التعبيرات المعقدة التي نملكها ، لأنها تجربه إنسانية عميقة ، ففي الأزمنة القديمة كان الفنان المصري القديم يرسم حكامه على حوائط المعابد و على الميداليات و العملات ويصور هم في تماثيل نصفية كبورتريه ، وبعد ذلك في العصر الروماني كان الفنانون يهتمون بقواعد التشريح في فن

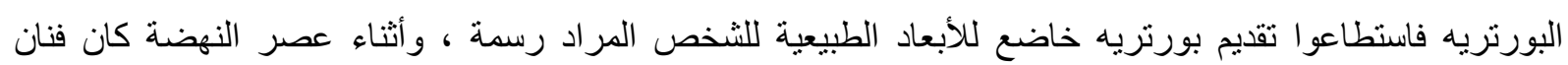

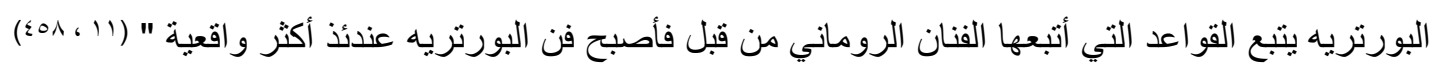

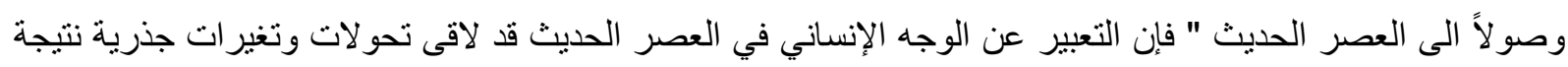
للتطور العلمي والتكنولوجي وتطور الرؤية والمفهوم وتتوع التفسير والمعالجات التشكيلية وتعميق الفكر التجريبى و الذى في لإنى

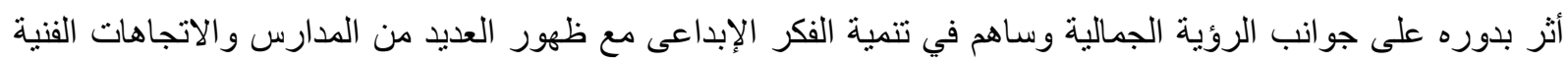

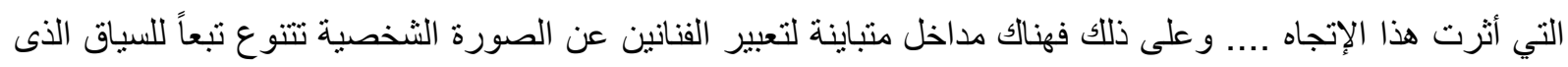


أنتج العمل في إطاره بما يتضمنه من متغير ات علمية وتكنولوجية و اجتماعية واقتصادية ترتبط بالهوية الثقافية للمجتمع ...

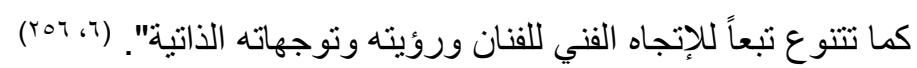
وقد" أهتم الفنانون القدامى بفن البورتريه من خلال أعمالهم الفنية سواء المرسومة بالألوان أو الأعمال النحتية.. وفى وفى

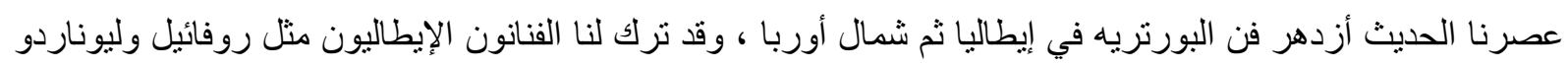

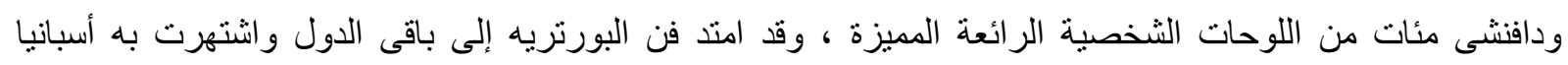

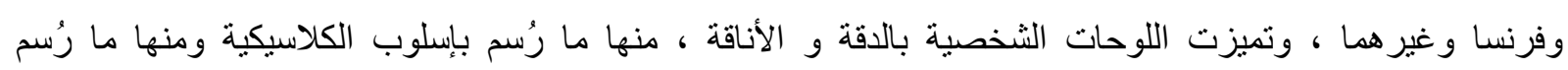

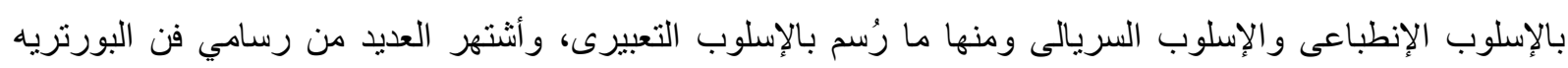

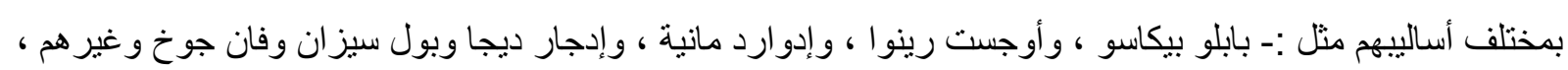

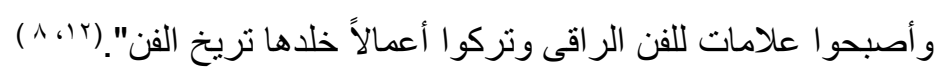

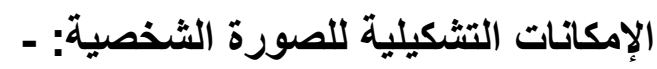
الصورة الثخصية " البورتريه " تعبر عن الملامح الظاهرية للشخص التي تكثف عن الروح والجوهر والانفعالات

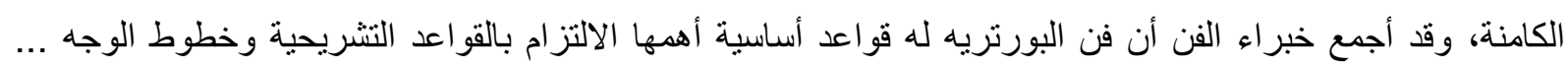
و هذا يتطلب التركيز على أعماق الشخصية للتعايش معها وليس فقط محاولة تسجيل ملامحها. بأخذ الوجه في البورنريه أوضاعاً متعددة (10):

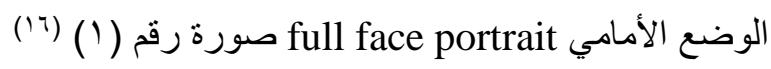

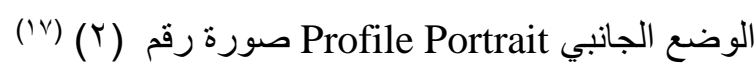

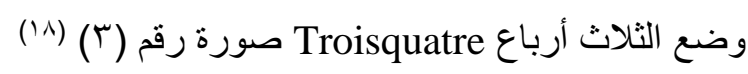
ويعد الوجه من أهم أجزاء الصورة الثخصية فمنه تتضح الانفعالات والأحاسيس والانطباعات ومن خلاله يتم التواصل بين المتلقي أو المتذوق وبين العمل الفني المنسوج، فالعين تلعب دور رئيسى في تفاعل المتلقي مع العمل الفني وكذلك الحاجبين و الثفاه والأنف من أجزاء الوجه التي تبرز الانفعالات المصاحبة للصورة النخصية. ولأن البورتريه أو الصورة الثخصية تعد مصدر التعبير الواضح عن الانفعالات و إظهار الحركة في بعض الأحيان فرسم الأنم

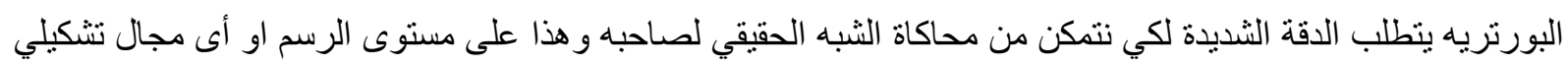
أخر، أما في حالة نسج البورتريه وهو ما نحن بصدده فإن الدقة المطلوبة تكون مُضاعفة حتى نتمكن من خلال الخيوط و إنحناءاتها أن نصل الى درجة عالية من الدقة لصياغة ملامح البورتريه وتسجيلها كما لو كانت مرسومهـ.

\section{المعالجات التصميمية للصورة الثخصية التى تتوافق مع التصميم النسجي الناجح:}

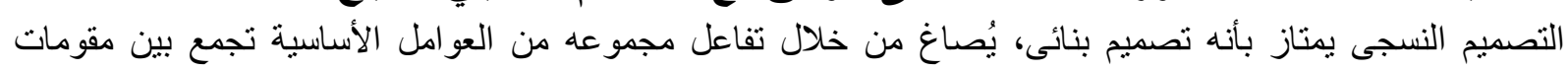

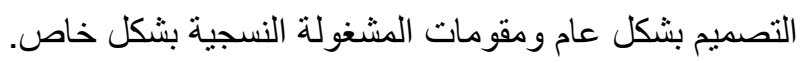

ويمكن أن نؤكد علي أن للتصميم النسجى الناجح عدة مواصفات من أهمها: -

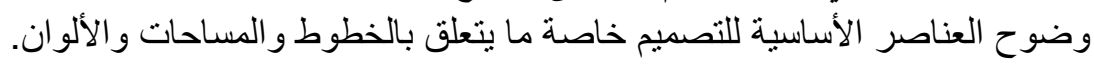
تكاملية الشكل و الأرضية على سطح المشغولة النسجية. البعدعن كثرة التفاصيل الدقيقة مراعاةً لإمكانات الخامات النسجية فكلما كثرت التفاصيل في التصميم صعُب تنفيذها بالخيوط. 
كلما كانت الخطوط في التصميم عكس اتجاه خيوط السداء كلما كان تنفيذها أدق على سطح المشغولة وبالتالي يكون الجزء التعبيرى أقوى و أوضح. يتحقق فيه الثراء اللوني. وفى ضوء هذه المواصفات للتصميم النسجى الناجح، كان لابد من إتباع ومر اعاة مجموعه من القواعد عند تحديد إلتقاط اختيار الصورة الثخصية الذاتية موضوع التصميم النسجى للبحث حتى تتو افق معه: عند اختيار الصورة الثخصية يجب الاهتمام بالتفاصيل في الوجه و الرأس وتقليل التفاصيل بالجزء المتصل بالر أس وهو

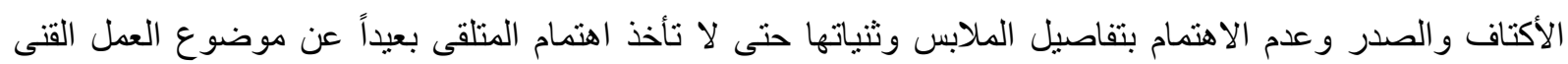
النسجى (الصورة الثخصية). مر اعاة الإضاءة المناسبة لإظهار التفاصيل وتحديد أماكن الظل والضوء مع الأخذ في الاعتبار أن الإضاءة القوية لا تفيد، بل بالعكس ثُضيع الملامح و أفضل إضـاءة تُنير العمل هي الإضـاءة من الجهة المقابلة الجانبية. مر اعاة اختيار الخلفية المتوافقة مع التصميم وأن تكون بسيطة بعيده عن التفاصيل الزائدة حتى تكون مكملة للصورة، ويفضل أن تكون ألوان الخلفية بها تباين بين الفاتح و الغامق وبها درجة إضاءة مناسبة مأخوذة من الدرجات اللونية المكونة

$$
\text { للصورة حتى تدعم من ظهور ها ـ الصورة الثخصية (البورنريه)-. }
$$

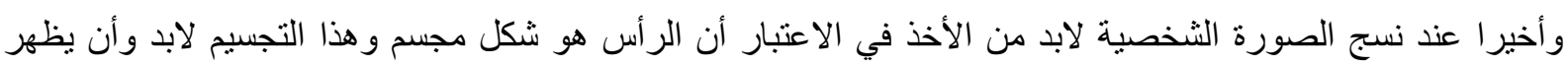

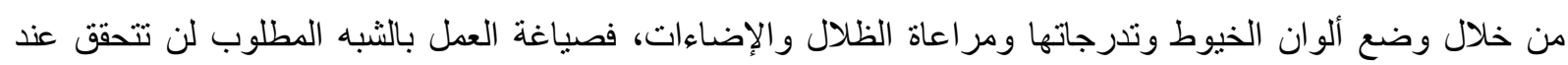
نسج ملامح الوجه فقط، بل من خلال الإيحاءات الخاصة كالتجسيم بالتدرجات اللونية للخيوط وملمس الجلد و الثُعر حتى ونى ونى نصل الى رؤية مكتملة مقبولة تشكيلياً على السطح المنسوج اللعمل الفني. وفى هذا البحث تم الاعتماد على الصورة الثخصية الذاتية للطلاب عينة البحث ـ كنوع من التحفيز للالتزام و المثابرة

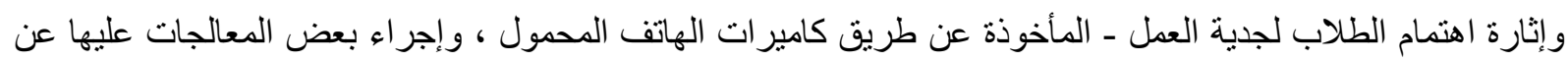
طريق إعدادات تعديل الصورة الخاصة بالهاتق Photo Editing كمدخل طلابي بسيط ليس له علاقه بتكنولوجيا

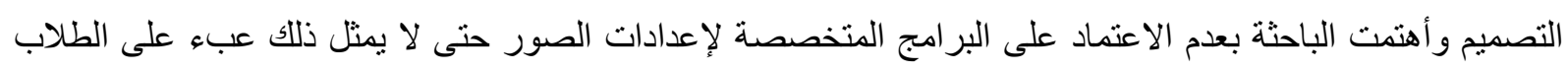

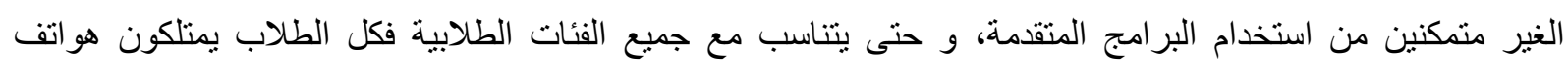

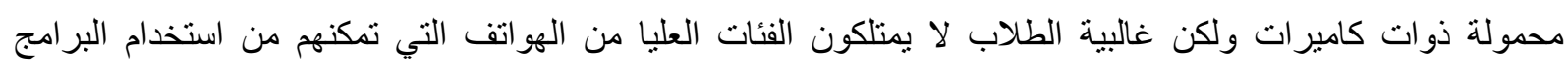

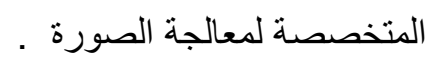
و هذه المعالجات تمثلت في تحليل الصورة الثخصية وتقسيمها الى مساحات واضحة تُمكننا من تحديد كل التفاصيل الكامنة بالوجه، ومن ثَمَ تحديد التفاصيل اللونية لكل مساحة حتى إذا ما بدأنا في عملية النسيج نقوم بنسج كل مساحة بكل تفاصيلها اللونية والملمسية على النول الى أن نصل الى عمل فنى نسجى ناجح ومكتمل. إضافة الى أن هذه الخطوة وهي تقسيم الصورة الثخصية (البورتريه) الى مساحات واضحة تمكننا من الاستغناء و البعد عن التفاصيل الزائدة، حيث أن المبالغة في التفاصيل تؤدى الى تشويه العمل عند النظر اليه خاصة عند النظرة الكلية المشغولة (1) (من أعمال المجموعة الضابطة) كما أن استخدام الصورة الفوتوغر افية أو الرقمية تحافظ على ثبات الزاوية والحالة ووضع الصورة الثخصية وثبات الإضاءة، فنبات وضع وحالة الصورة الثخصية ومحاولة النساج إبرازهما من أهم العناصر المساعدة لإنجاح العمل الفن 
إضافة الى ثبات تعبيرات الوجه ووضعه تجنباً لوقوع الخطأ، فالخطأ النسجى من أصعب الأخطاء عند بناء العمل النسجى، فتصويبه يتطلب إز الة كل اللحمات المنسوجة في هذه المساحة وهذه الخطوة تحديدً فيها من الصعوبة أضعاف ما يتطلبه

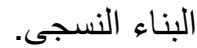
ولتحقيق هذا على حيز التنفيذ كان لابد من إتباع طريقة نسجيه من شأنها أن تُكننا من الرسم بالخيوط وكأنها ريشة فنان، طريقه فنية تمكننا من إيجاد كل التفاصيل الثكلية و اللونية و الملمسية لصياغة العمل الفني بطريقة دقيقة ناجحة.

\section{النسيج المرسم (التابسترى Tapestry):}

النسيج المرسم، القباطي، التابسترى ، كلها مر ادفات لمعنى واحد وهو نوع من النسجيات ذات طابع زخرفي، يستخدم في نسجها أسلوب اللحمات غير الممتدة في عرض المنسوج، ويمتد جذور هذا الفن فن النسيج المرسم الى الحضارة المصرية القديمة ،وفيه تتجاور اللحمات الملونة كلاً في المساحة المخصصة لها وفقاً للتصميم ، وينم فيها تغطية خيوط السداء تماماً فالسداء هنا ما هو إلا حامل لخيوط اللحمة ، فتظهر اللحمة على وجهى المنسوج بينما بظهر السداء على هيئة تضليعات بسيطة في كلا الاتجاهين ويحكم ظهور هذه التضلعات اختلاف تخانة خيوط السداء عن تخانة خيوط اللحمة، وفى معظم

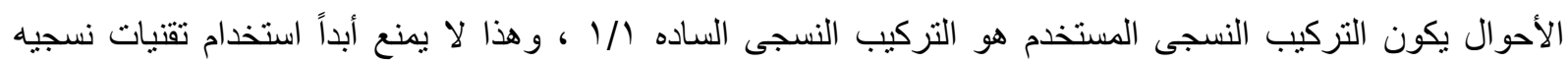
زخرفية أو حتى أساليب نسجيه أخرى، فيمكن التتوع بينهما كلما اقتضت حاجة العمل الفني لذلك في ضوء التصميم وما

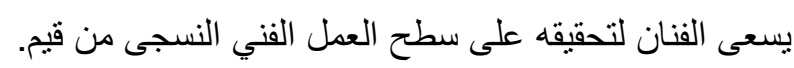
و النسيج المرسم من الأساليب الزاخرة بالقيم الفنية والتشكيلية، و استخدامه يمكننا من صياغة ونسج لوحات تصويرية مليئة

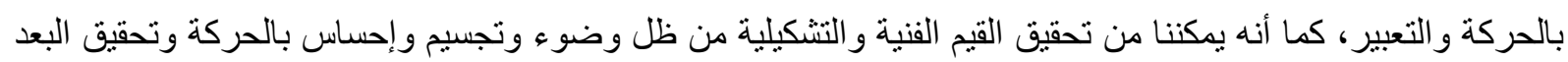
الثالث عن طريق استخدام خيوط مختلفة من حيث الخامة و التخانة و اللون، وكل ذلك وفق مُنطلبات التصميم النسجى.

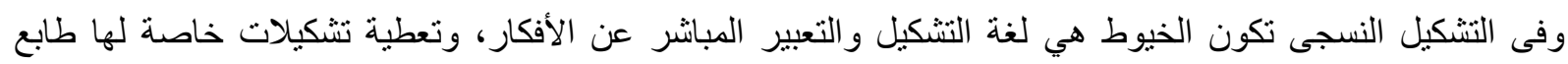

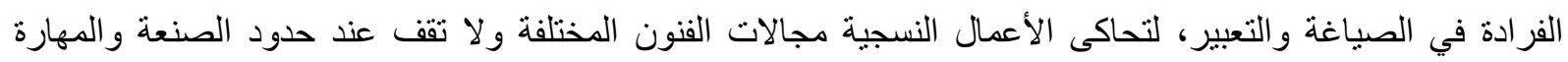
الأدائية ، فالخامة إمكاناتها التشكيلية وللتقنية إبداعاتها الزخرفية، وعندما تجتمع كلاهما يُستثمر ذلك في تحقيق إبداعات نسجيه متفردة ذات قيمه فنية وتتكيلية رفيعة المستوى.

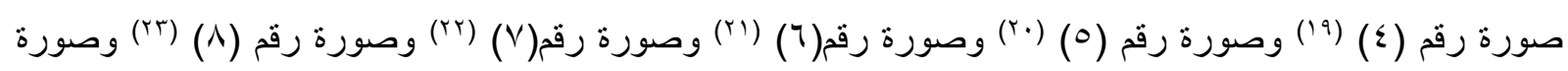
رقم (9) (צ׳) مجموعة من الأعمال الفنية النسجية التي جمعت بين الإمكانات التشكيلية للصورة الثخصية وبين الإمكانات الإبداعية للنسجيات اليدوية. 


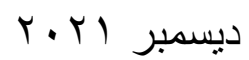

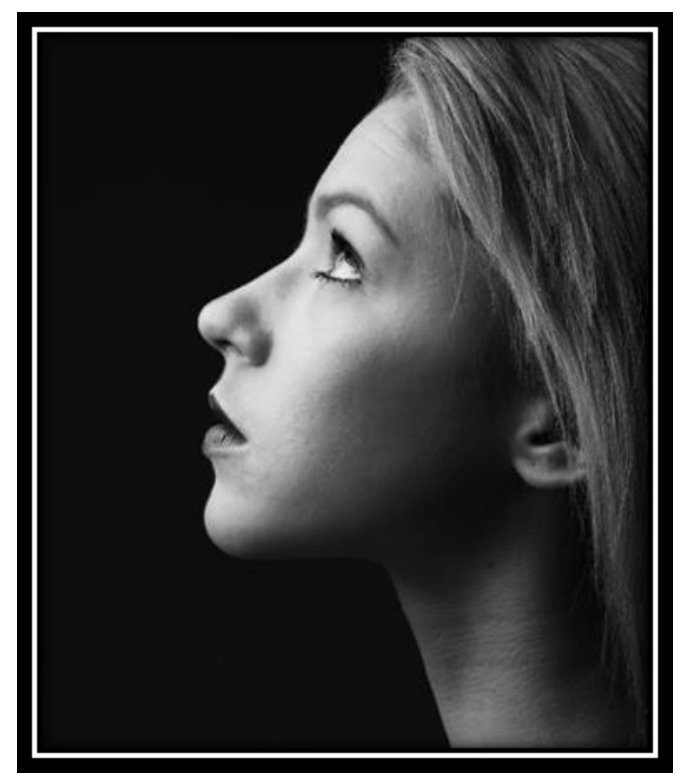

صورة رقم (r)

تبين الوضع الجانبى للصورة الثخصية
مجلة التراث والتصميم ـ المجلد الاول ـ العدد السادس

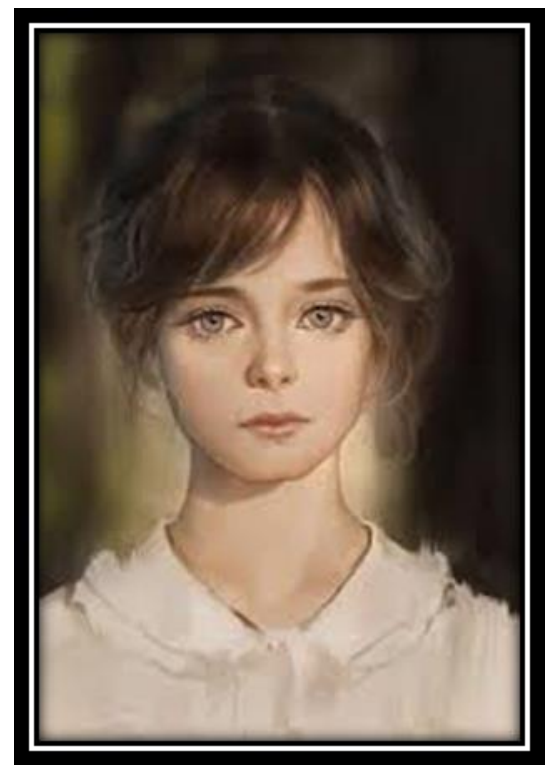

صورة رقم (1)

تبين الوضع الأمامى للصورة الثخصية

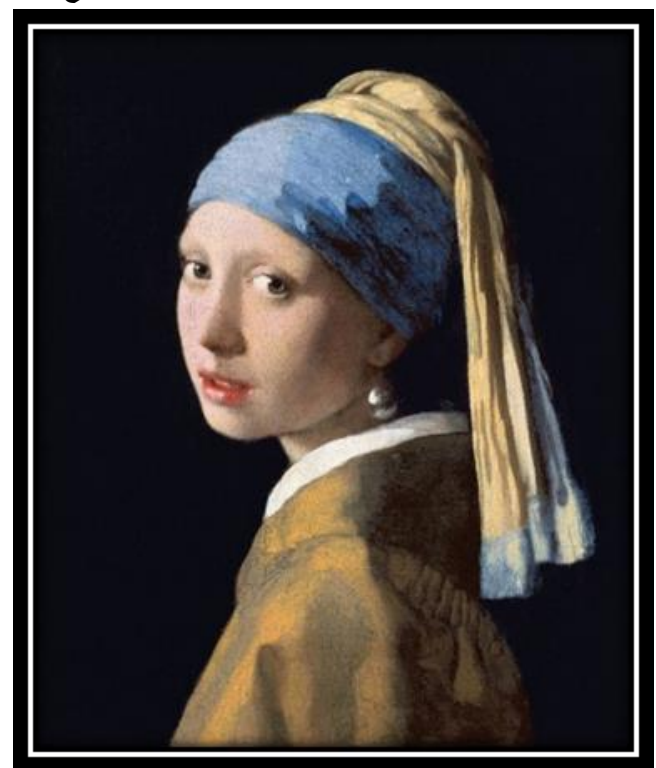

صورة رقم ()

تبين وضع الثلاث أرباع للصورة الثخصية

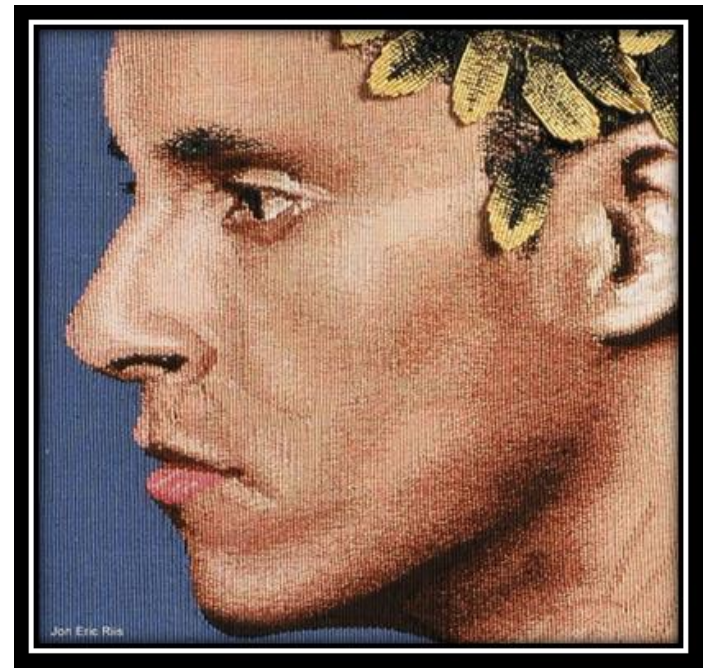

صورة رقم (0)

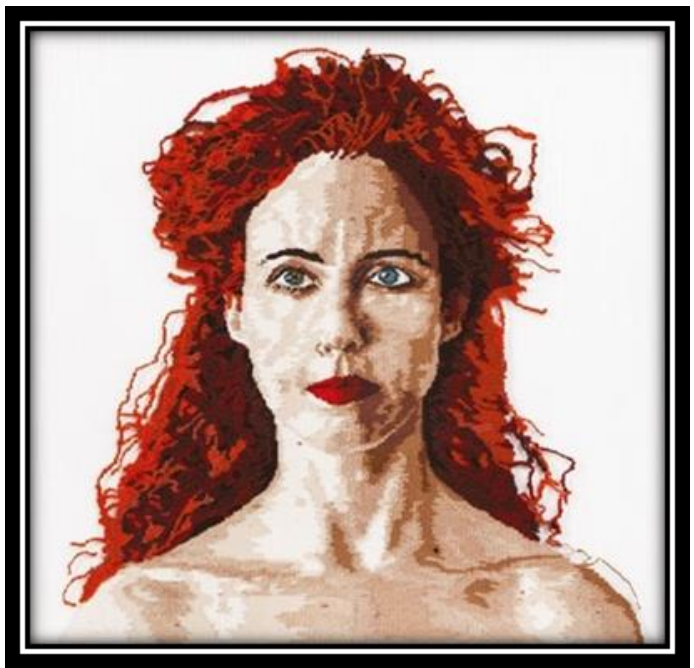

صورة رقم (؛) 


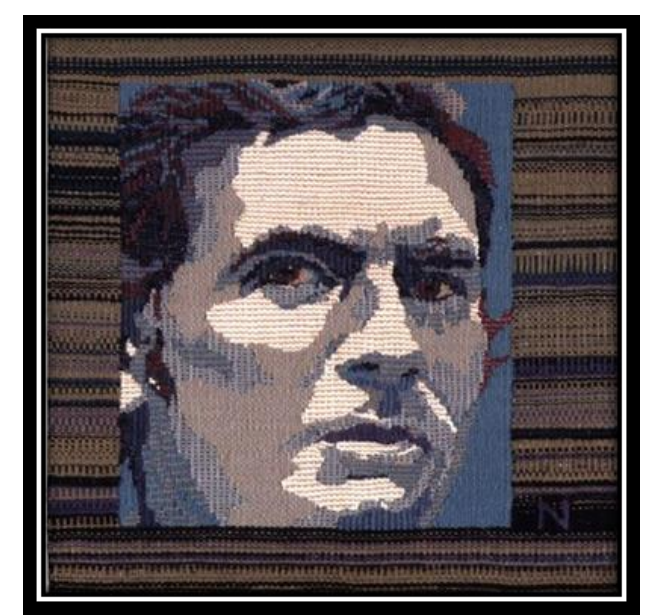

صورة رقم (V)

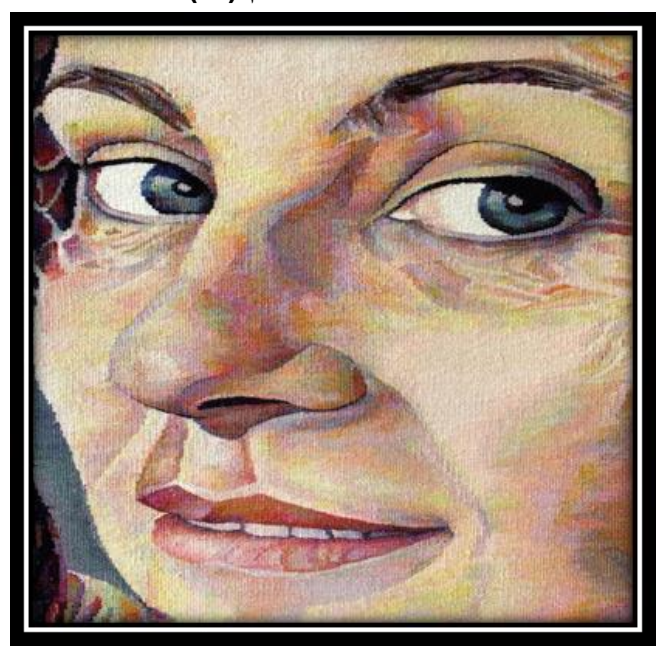

صورة رقم (9)

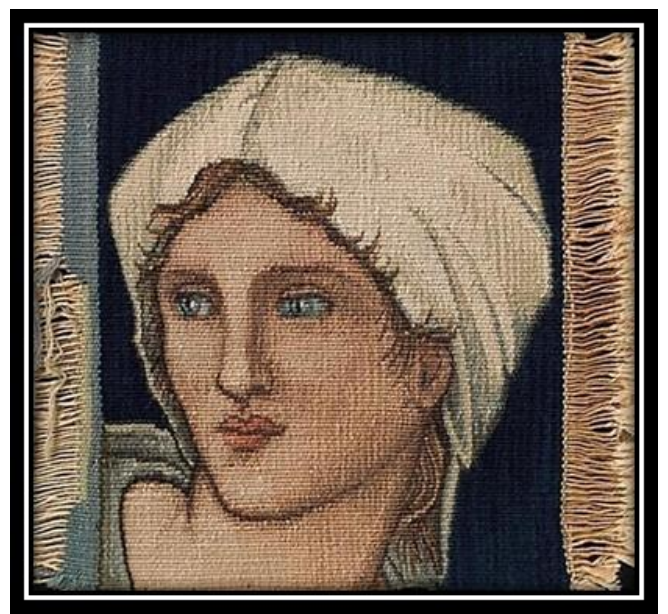

صورة رقم (1)

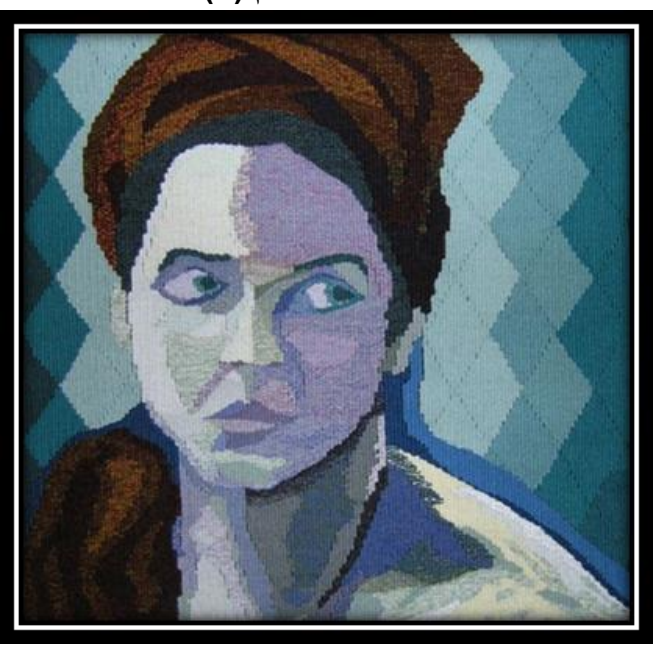

صورة رقم (^)

الار اسـات السابقة والمرتبطة:

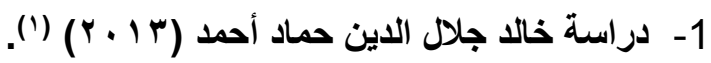

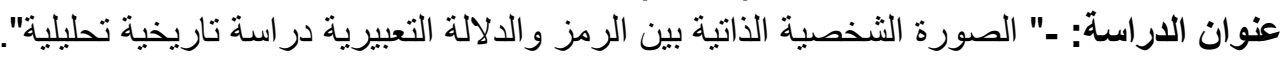
هدفت الاراسة الى: - الكثف عن أهمية الصورة الثخصية الذاتية للفنان جمالياً وتعبيرياً. وتوصلت الي مجموعة من النتائج من أهمها: - أن الصورة الثخصية الذاتية للفنان هي ما تعكس أفكاره عن حياته وما يحيط به من موجودات والسياق الذي يعيش فيه، فهى المنفذ الذي يستطيع من خلالها أن يعبر عن أفكاره الاجتماعية و السياسية وحتى الدينية.

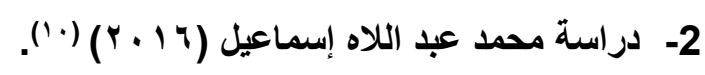
عنوان الاراسة: -" سمات الصورة الثخصية (البورتريه) في الفن التجميعي المعاصر". هدفت الدراسة الى: - التعرف على سمات الصورة الثخصية في الفن التجميعي المعاصر. وتوصلت الي مجموعة من النتائج من أهمها:

أن جميع الأعمال التي تتاولتها الدراسة أكدت الثباه الفيزيائى بين الصورة المنتجة بطريقة الأسمبلاج و الثخصية الحقيقية، كما أنه يتنوع حجم الصورة الثخصية المنتجة بطريقة التجميع (الإسمبلاج) ما بين الحجم الطبيعي والأحجام الكبيرة المبهرة و التي يحتاج بعضها الى الاف القطع للتنفيذ ووجود مساحات كبيره بين العمل و المتلقى كمجال للرؤيا. 
عنوان الاراسة: - " القيم التنكيلية والتعبيرية للبورتريه كمنطلق لإستحداث صياغات طباعية" هدفت الدراسة الى: - استثمار جماليات التعبير للوجه الأدمى "البورتريه" لإستحداث صياغات طباعية تفيد في العملية التعليمية بمجال التربية الفنية.

وتوصلت الى مجموعة من النتائج من أهمها: ـ أمكن استحداث صياغات طباعبة قائمة على القيم التشكيلية للوجه الأدمى " البورتريه ".

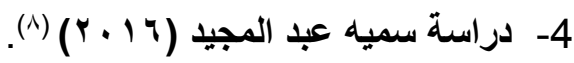
عنوان الاراسة:" المتغير ات التشكيلية في الأعمال الفنبة النسجية المصرية المعاصرة". هدفت الاراسة الى: - التعرف على المتغيرات التشكيلية في الأعمال الفنية النسجية المصرية المعاصرة. وتوصلت الى مجموعة من النتائج من أهمها :- حدث تطور في الأعمال الفنية المعاصرة من حيث التصميم والخامة و أساليب التعانقق و الصياغات التشكيلية، كما أن العمل النسجى تحرر من الإرتباط بالوظيفة كأساس للتصميح.

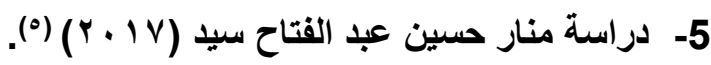
عنوان الدراسة: "الاتجاهات المعاصرة للنسجيات البدوية كمدخل لإستحداث تذكار ات سياحية". هدفت الاراسة إلى: - الكثف عن رؤية تشكيلية جديده من خلال الاستفادة من الاتجاهات المعاصرة للمنسوجات اليدوية في الجمع بين أكثر من أسلوب تقني وصياغة تشكيلية في المشغولة النسجية. وتوصلت الى مجموعة من النتائج من أهمها: أن استخدام الاتجاهات المعاصرة للنشكيل النسجى أعطت ثراء للمشغولة من حيث التقنيات والخامات والتراكيب النسجية المختلفة، كما أن الدمج بين الخامات والتقنيات و الأساليب التنكيلية المعاصرة بداخل العمل الواحد أتاح المجال لحرية الممارسة والإبداع الى جانب ابتكار صياغات تشكيلية جديده وإبراز تأثثر نوع الخامة المستخدمة على الجانب الوظيفي للتنكار.

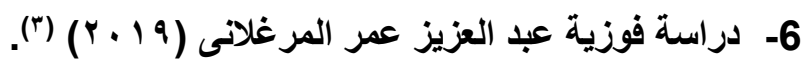
عنوان الاراسة: - "القيم الدلالية للصور الثخصية كمدخل لتصميم مجسمات معدنية " هدفت الدراسة الى مجموعة من الأهداف من أهمها الكثف عن الجماليات التعبيرية والقيم الدلالية للصور الثخصية لإنتاج مجسمات معدنية معاصرة. وتوصلت الى مجموعة من النتائج من أهمها: - أن الفنان يستطيع الاستفادة من الدلالات الرمزية للصورة الثخصية ليعبر عن الانفعالات الإنسانية في صورة مجسمات معدنية تحمل مضامين متنو عة.

7عنوان الاراسة: -" الأبعاد التشكيلية والمفاهيمية لفن البورنريه المعاصر كمدخل لتأكيد الهوية الهية الثقافية ". هدفت الاراسة إلى: - دراسة وتحليل مختارات من فن الصورة الثخصية " البورتريه" المعاصر لتحديد المنطلقات التتكيلية و المفاهيمية التي يمكن أن تسهم في تأكيد الهوية الثقافية. وتوصلت الى مجموعة من النتائج من أهمها: - أن استلهام الصور الثخصية من الموروث الثقافي العربى وتفسيرها بصرياً يسهم في تعميق الهوية الثقافية العربية. 


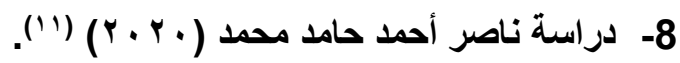

عنوان الدراسة: " الإبداع الرقمي لإحياء فن البورتريه الأفيش السنيمائي الجرافيكي كعنصر نرويجي فعال لدراما الروايات السينمائية المصرية". هدفت الدراسة الى: - يهدف البحث الى محاولة توظيف فن البورتريه في تصميم الأفيش السينمائي من خلال مر اعاة حدود الدراما الروائية الخاصة بالفيلم السنيمائي المر اد الإعلان عنه. وأهم ما توصلت إليه الاراسة من نتائج: يُعد البورتريه الجر افيكي الرقمي الموظف في الأفيش السنيمائي عنصر اً مهماً في نشر الفن التشكيلى الر اقى في الثنارع.

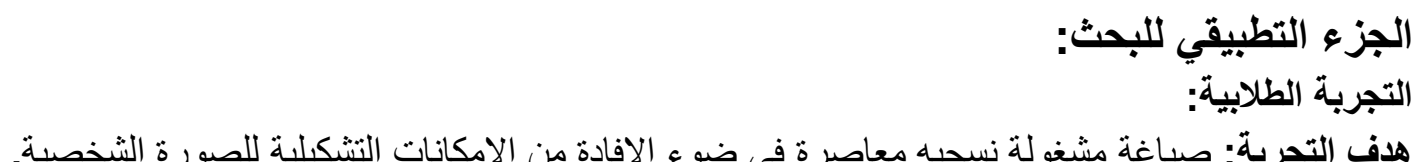
ثوابت التجربة: ـ الحدود الموضوعية للتجربة هئة الاستفادة من الإمكانات التشكيلية للصورة الثحصية.

الاعتماد على الصورة الثخصية الذاتية للطلاب عينة البحث كنوع من التحفيز للإلتزام والمثابرة و إثارة اهتمام

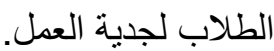
الاستعانة بكاميرات الهاتف المحمول لإلتقاط الصورة الشخصية.

المعالجات التصميمة للصورة الثخصية معتمدة على بعض طرق معالجة الصورة على الهاتف المحمول كمدل طلابي بسيط ليس له علاقة بتكنولو جيا التصميم المتقدمة، ولكن تربطه علاقة بسيطة بتكنولوجيا التصميم. الطريقة النسجية المستخدمة: إسلوب النسيج المرسم حيث اللحمات غير الممتدة في عرض المنسوج ونسجه وتتفيذه بالتركيب النسجى السادة // وتقنية السوماك المفرد. الخامات المستخدمة: استخدام خيوط الصوف الصناعي متعدد التخانات وخيوط القطن و الحرير.

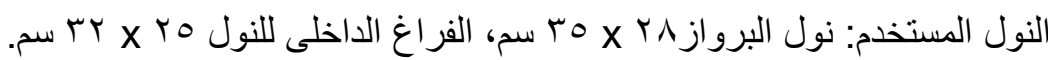

تتكون عينة البحث من • ب طالب وطالبة من طلاب الفرقة الثانية، كلية التربية الفنبة، جامعة المنيا، للعام الجامعى

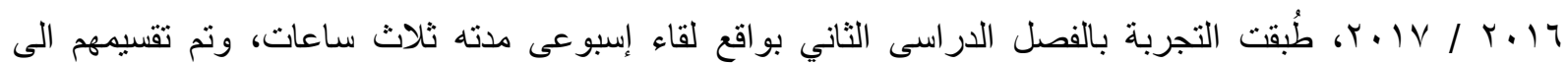
مجمو عتين متجانستين ضابطه و تجريبه بشكل عشو ائى.

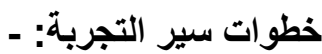
تم شرح و إيضاح الثوابت الموضوعية للتجربة ثم قدمت الباحثة الى طلاب كلا المجموعتين الضابطة والتجريبية نماذج لمجموعة من الأعمال النسجية المعتمدة في تصميمها على الصورة الثخصية للكثف عن بعض الإمكانات التشكيلية

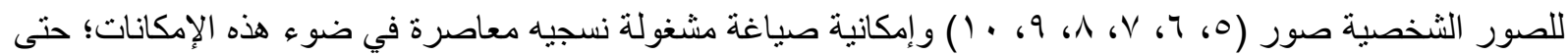
تكنمل عندهم الرؤية الذهنية للبدء في خطوات التنفيذ وصو لا للعمل النهائي وذلك وفق ... مجمو عة من الخطوات المتتابعة و التي يمكن عرضها كالتالي: الخطوة الأولى: مشاهدة ومدارسة مجمو عه من الأعمال النسجية القائم تصميمها على الصورة الثخصية. 
الخطوة الثانية: في ضوء الاستفادة من مدارسة الخطوة الأولى يبدأ الطلاب في إحضار مجموعه من الصور الثحصية

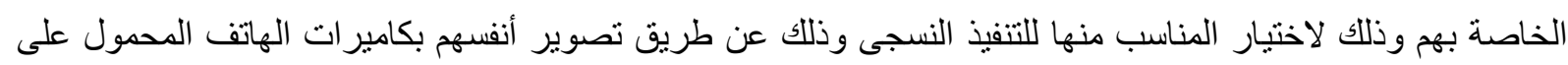
طريقة ( السيلفى). الخطوة الثالثة: اختبار صورة شخصية لكل طالب، ومن ثَمَ إجراء المعالجات التقنية على الصورة باستخدام بعض طرق معالجة الصورة على الهاتف حيث تقسيمها لمساحات وفق الأسس البنائية لها بما يتناسب مع مو اصفات التصميم النسجى. الخطوة الرابعة: ضبط المساحات الثكلية والدرجات اللونية بين الفاتح والغامق للحفاظ على هوية الصورة بعد تقسيمها. وبعد اختبار الصورة الثخصية المناسبة لكل طالب وتقسيمها الى مساحات وفق الأسس البنائية لها وضبط التباين والتوافق اللونى الذي يظهر من خلاله مجموعة من القيم اللونية التي تظهر إمكانات الصورة الثخصية التعبيرية و التشكيلية وتتناسب مع التصميم النسجي ـ، وبها نكون انتهينا من المر احل الأولية الأساسية السابقة لعملية التنفيذ. و هذه الخطوات الأربعة تم شرحها ومتابعة تنفيذها لكلا المجمو عتين الضابطه و التجريبه، وبعد الإنتقال للخطوات الأساسية للتنفيذ، قامت الباحثة بفصل المجموعة الضابطه عن المجموعة التجريبه على أن تقوم المجموعة الضابطه بالتنفيذ دون الإلتزام بأى قو اعد او خطو ات أخرى في ضوء ما تم فهمه و استيعابه من الخطوات الأربعة السابق ذكر هم. أما عن المجوعة التجريبية فسوف تقوم بالتنفيذ وفق مجموعة من الخطوات الأساسية الواجب إتباعها لصياغة عمل فل فنى نسجى مكتمل في ضوء متغير ات البحث وهي كالتالى: الخطوات الأساسية للتنفيذ: 1- 1 - تكبير التصميم للمساحة المطلوبة. 2- طباعة التصميم بالألوان طباعة جيده، فهو بمثابة الدليل اللونى للتصميم النسجى. 3- طباعة التصميم بالأبيض و الأسود كدليل خطى، وبيان نوضيحى للمساحات الو اجب نسجها وفق الدليل اللونى للصورة الشخصية. 4- تتبيت الدليل الخطى للصورة على ورق مقوى (الناصبيان) بالمساحة التي تتناسب مع مساحة النول لتتبيته أسفل

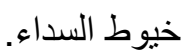
5- ت تجهيز النول وتسديته إستعدداً لبدء النسج. 6- تجهيز الخيوط - اللحمات- وضبط ألو انها وفق ألوان الصور الثحصية التي تم معالجنها وتثبيتها على النول. 7- بدء عملية النسيج بإسلوب النسيج المرسم حيث اللحمات غير الممتدة في عرض اض المنسوج. 8- عند بدء عملية النسيج لابد من الإلتزام بنسج المساحات التي تم تقسيمها بنفس شكلها وبنفس التفاصيل سواء التفاصيل عزيل الخطية أو اللونية أو التفاصيل الملمية حتى ينجح الطالب في محاكاة الثبه للصورة الثخصية على طريقة فن التصوير. 9- الإلتزام بالدرجات اللونية قدر الإمكان عن طريق تكوين اللون المطلوب من خلال خلط شعيرات الصوف من الألوان المناسبة لتكوين الدرجة اللونية المطلوبة وفق تصميم الصورة. 
أعمال المجموعة الضابطة:
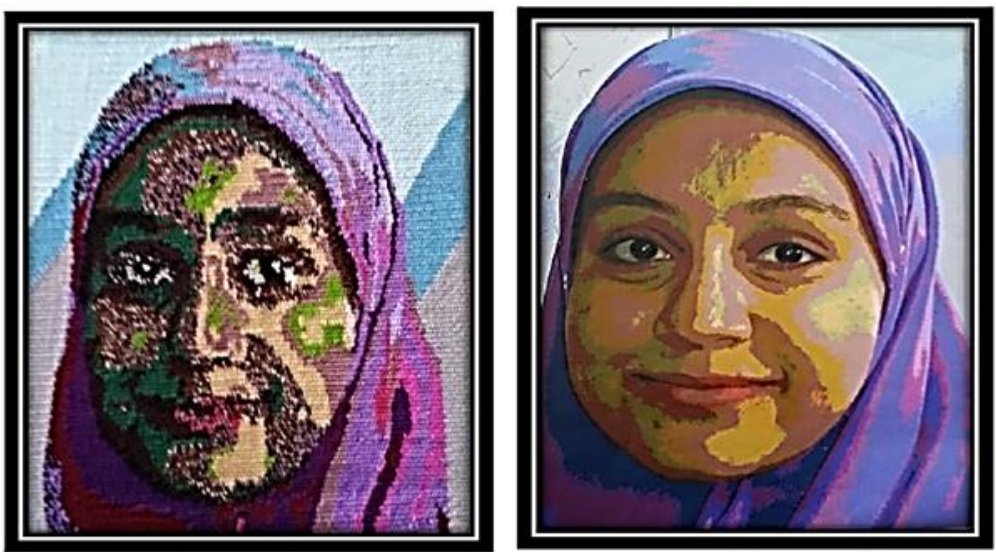

المشغولة (1)

التصميم (1)
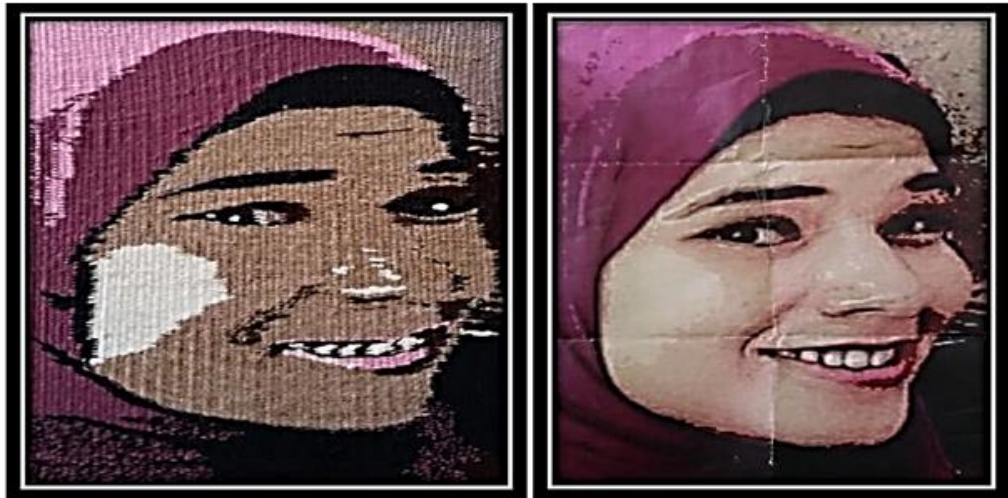

المشغولة (r)

التصميم (r)

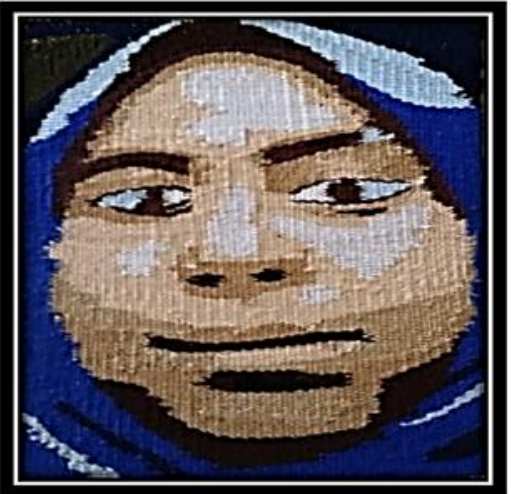

المشغولة (r)

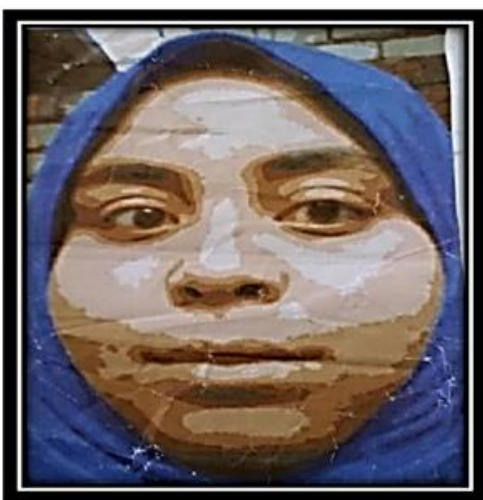

التصميم (") 

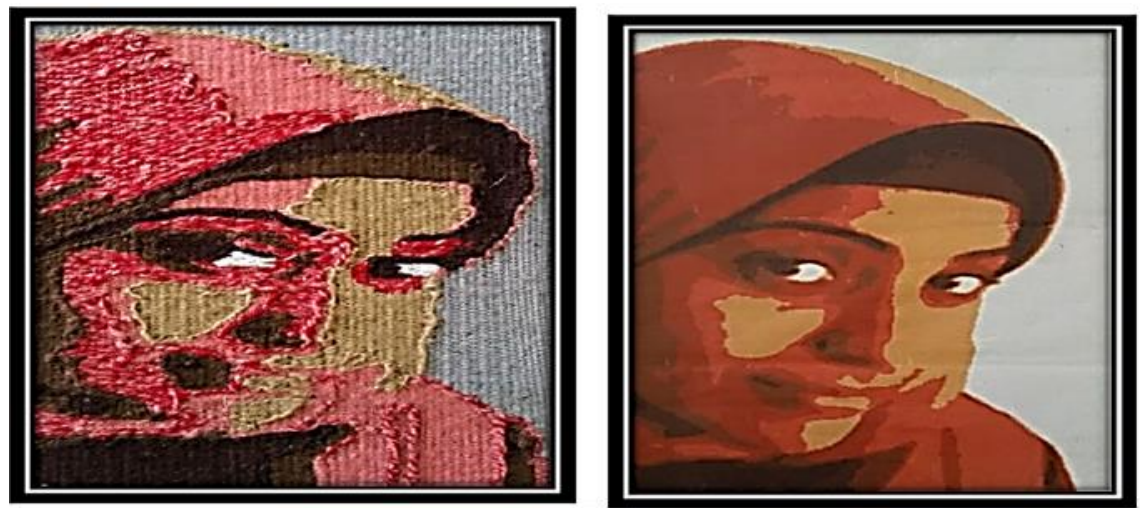

المشغولة (؛)

التصميم (؛)

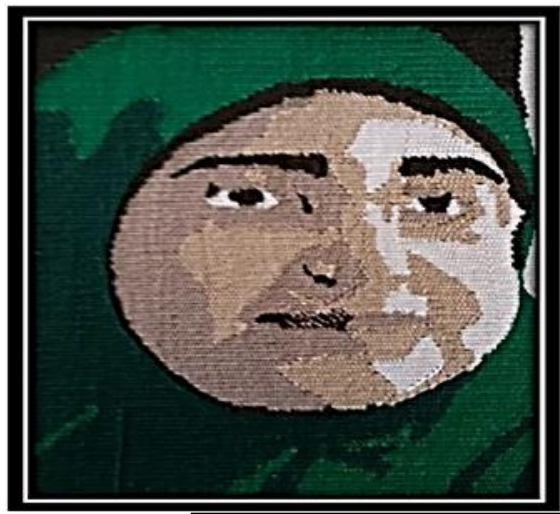

المشغولة (0)

(0) التصميم

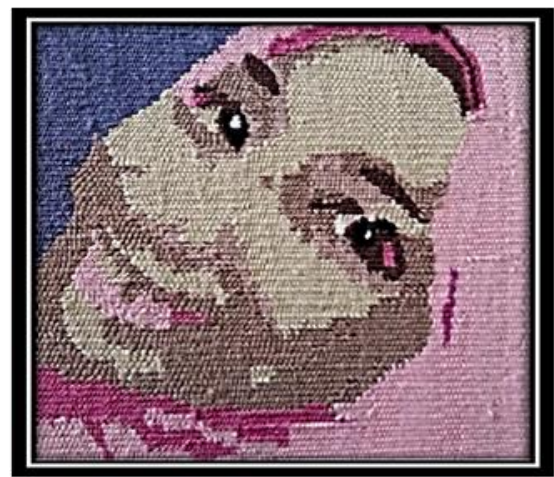

المشغولة (ך)
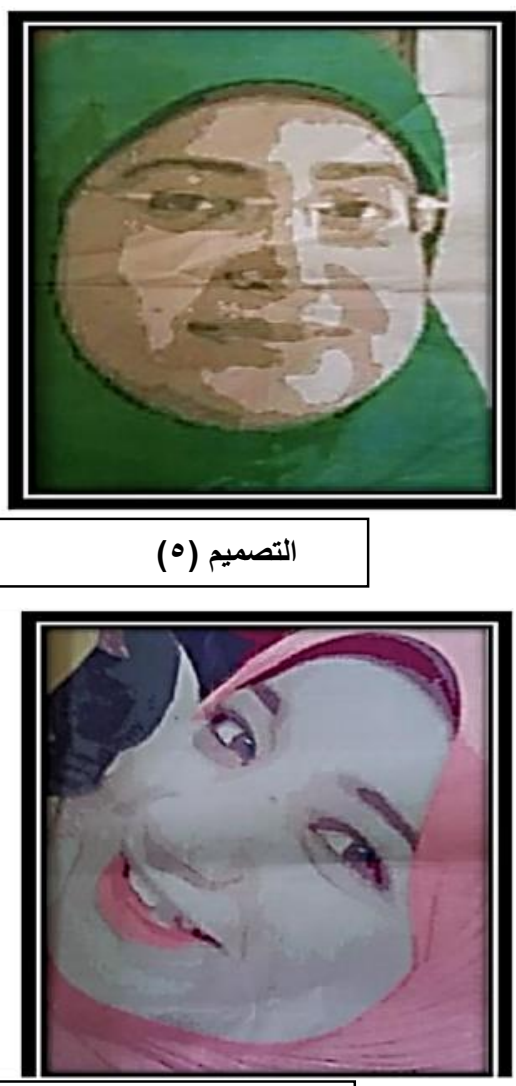

التصميم (1)

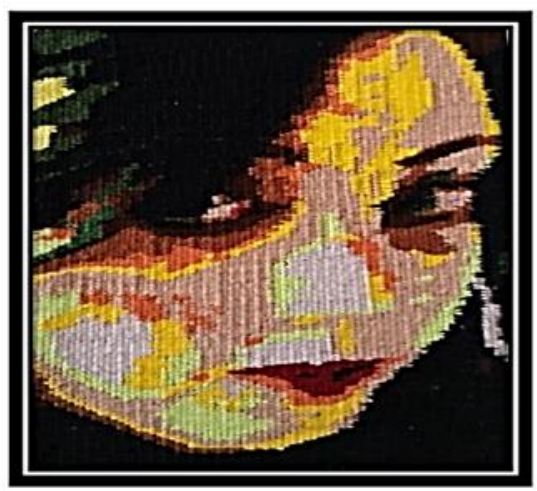

(V) المشغولة

(V) التصميم

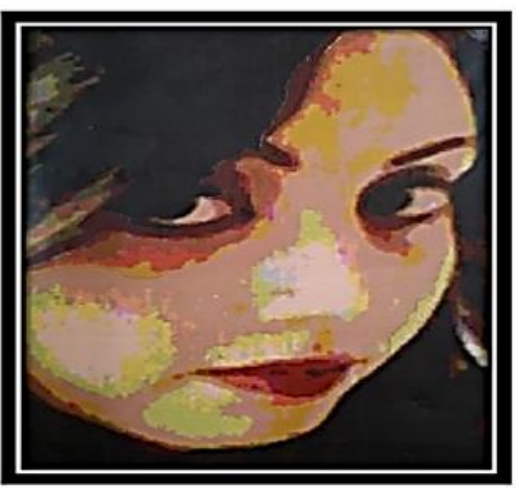



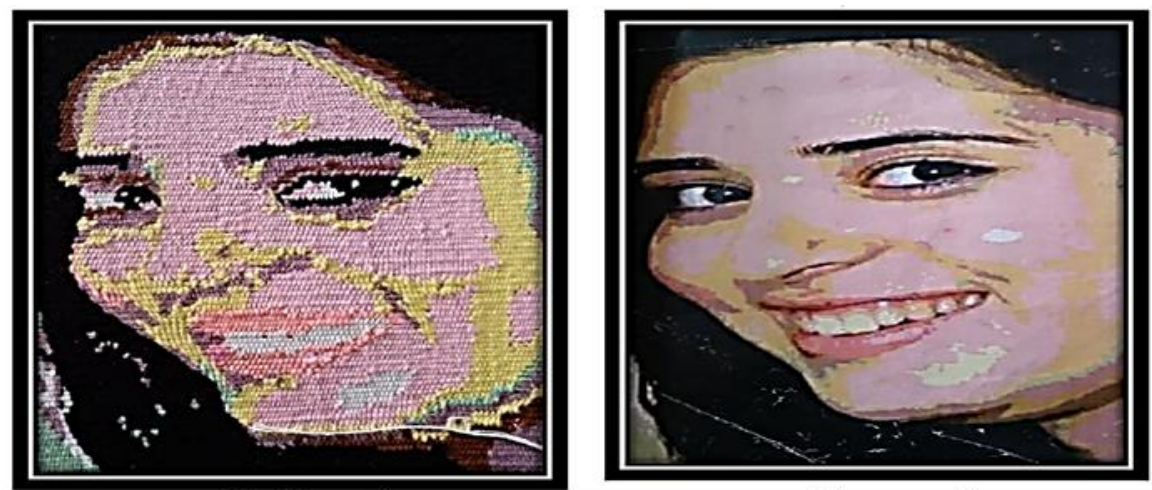

المشغولة (^)

التصميم (^)
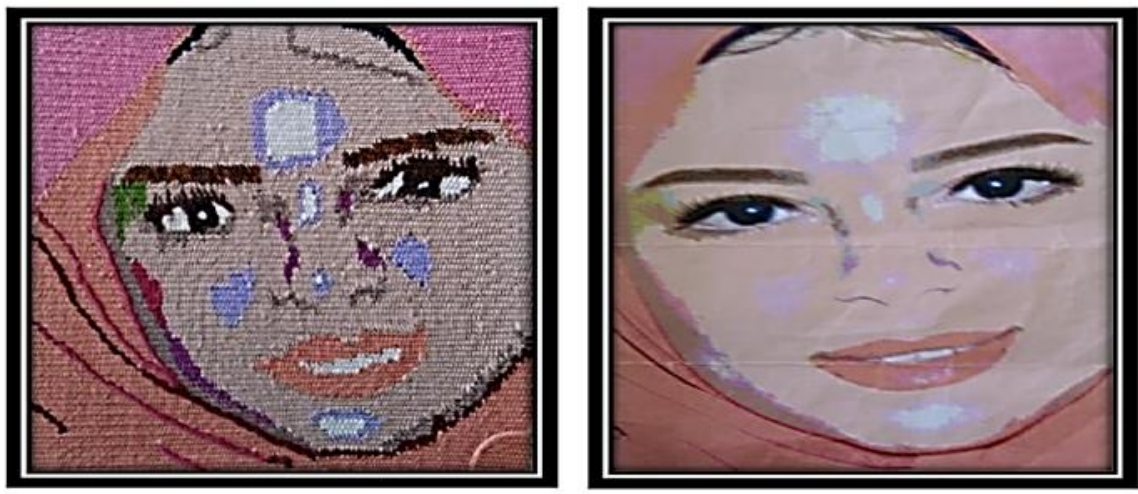

المشغولة (9)

(9) التصميم
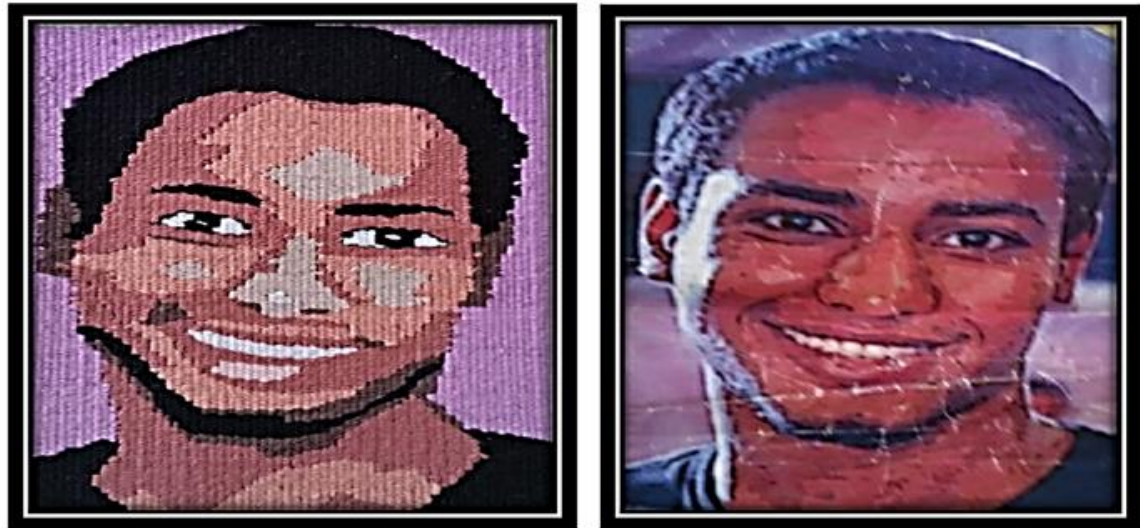

المثغولة (· (1)

التصميم (·1)

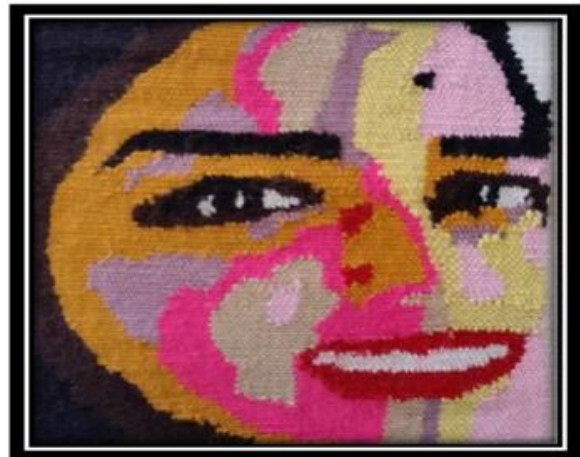

المشغولة (1')

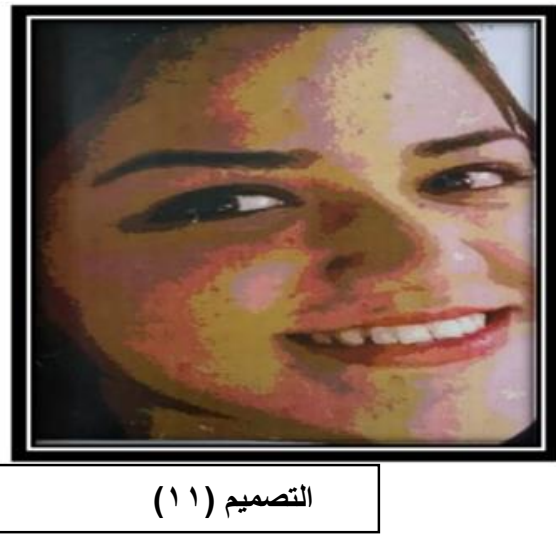



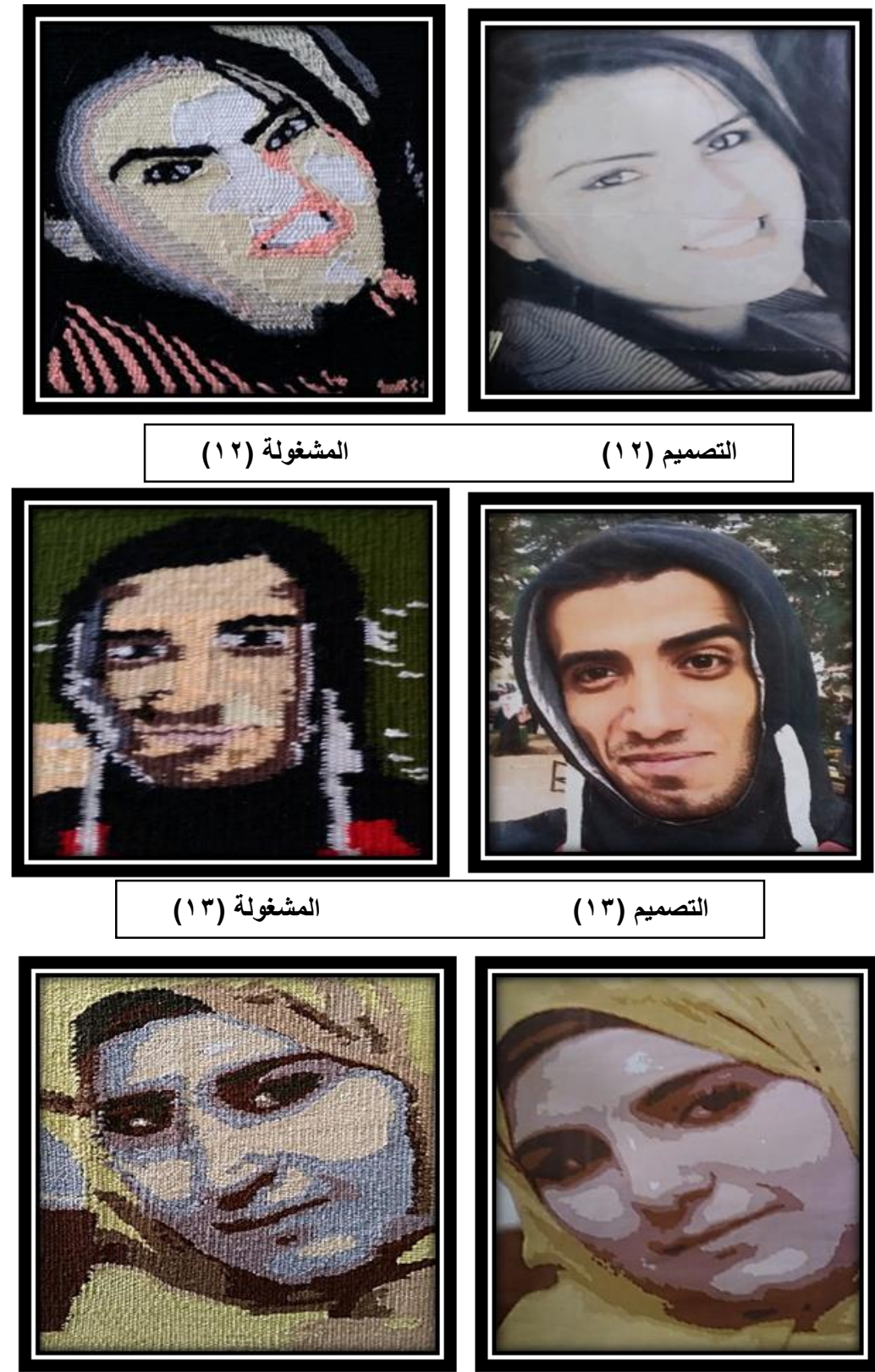

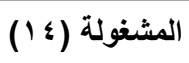

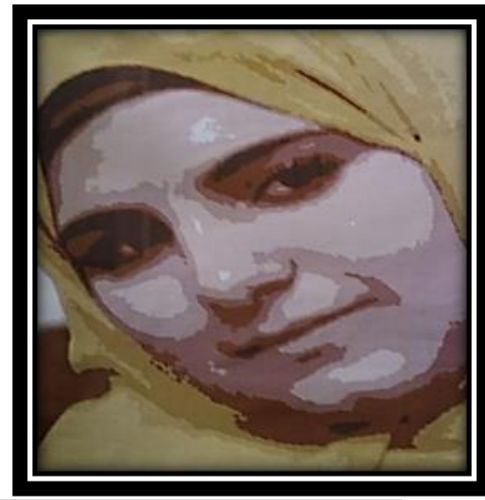

التصميم (1 (1)
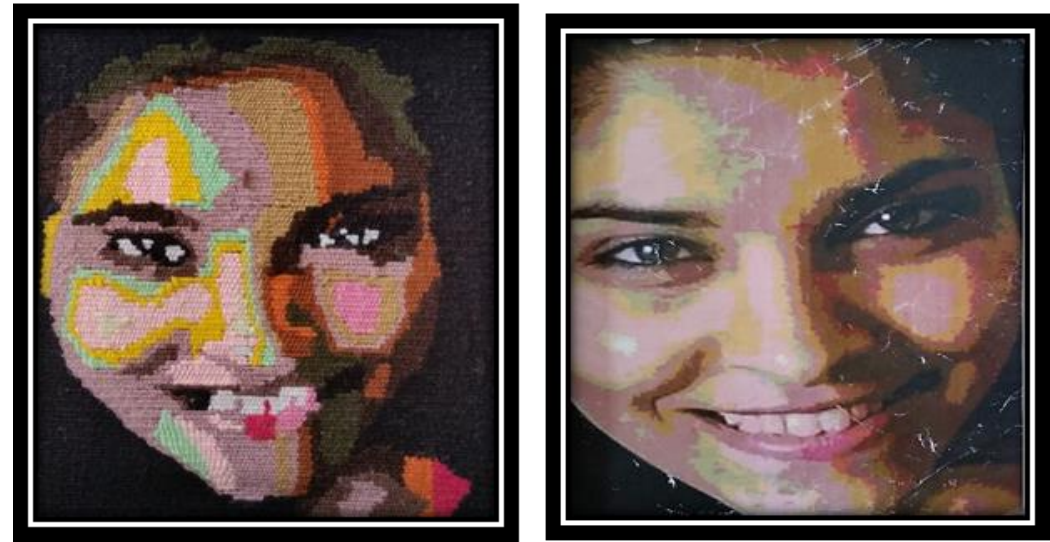

المشغولة (10)

التصميم (10) 
أعمال المجموعة التجريبية:

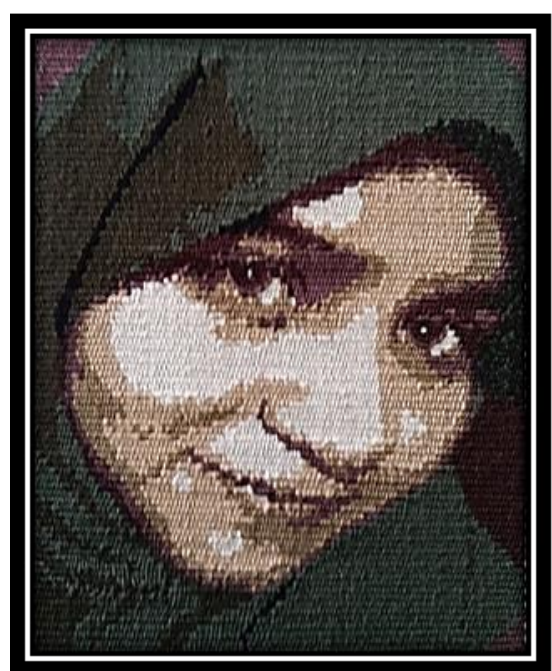

المشغولة (1)

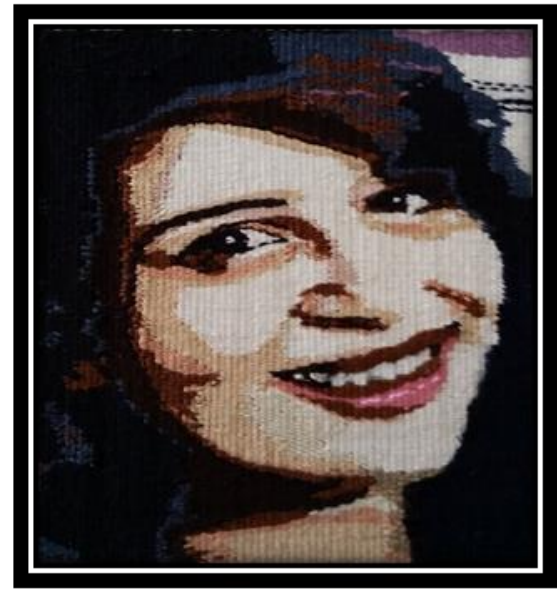

المشغولة (r)

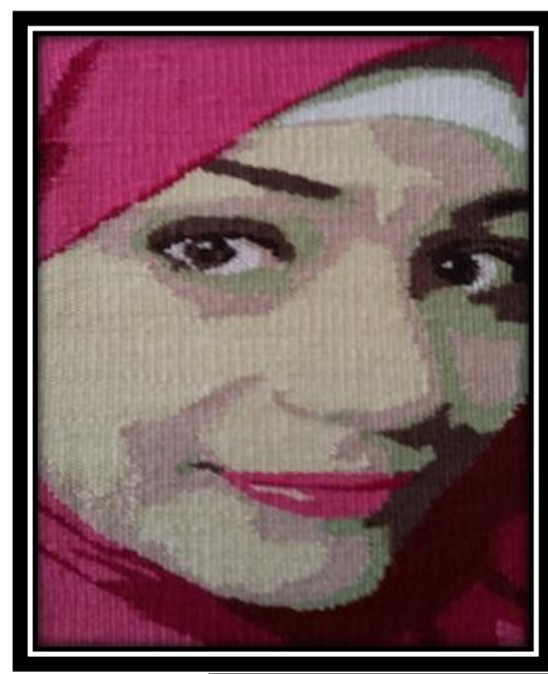

المشغولة (ॅ)

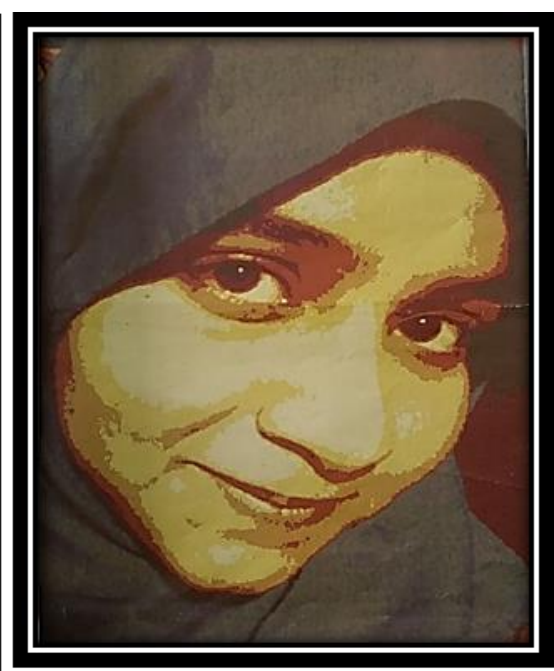

التصميم (1)

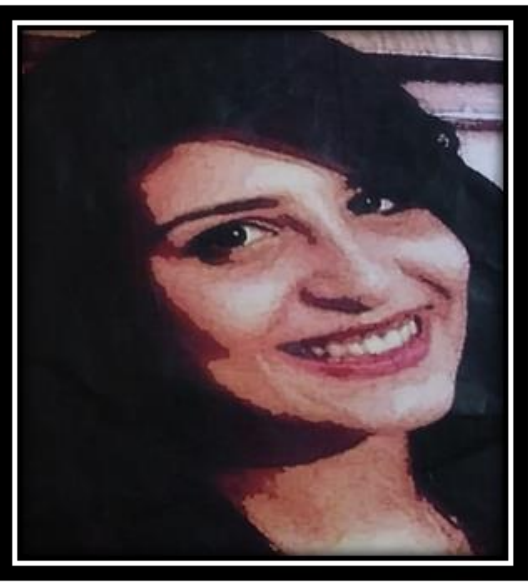

التصميم (r)

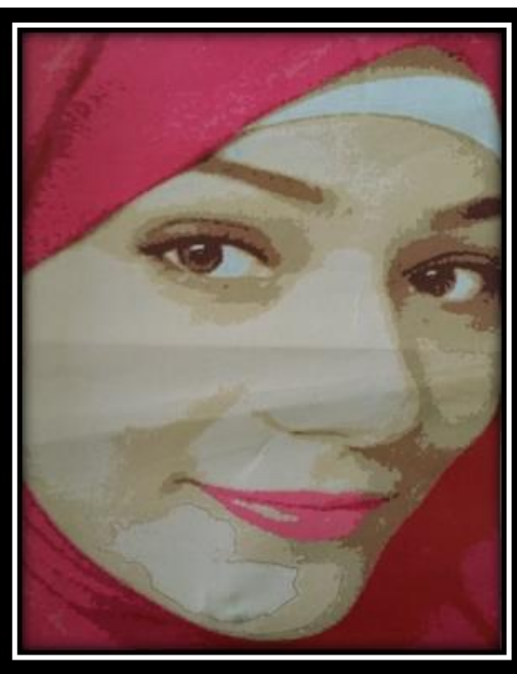

التصميم (") 


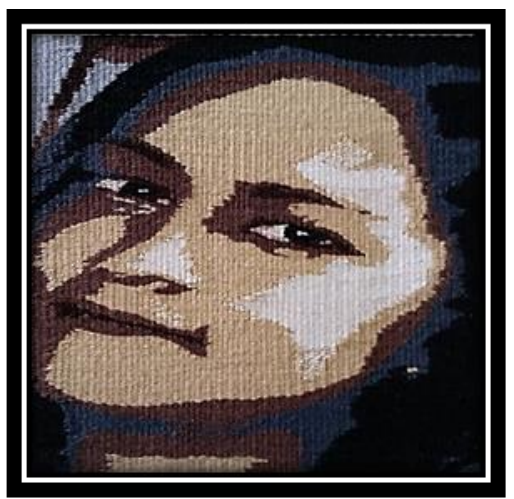

المشغولة (؛)

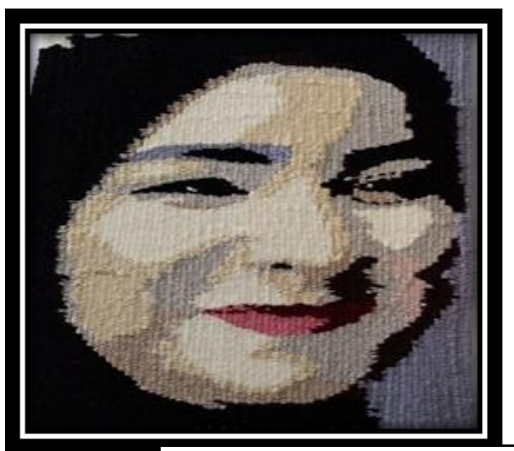

المشغولة (0)

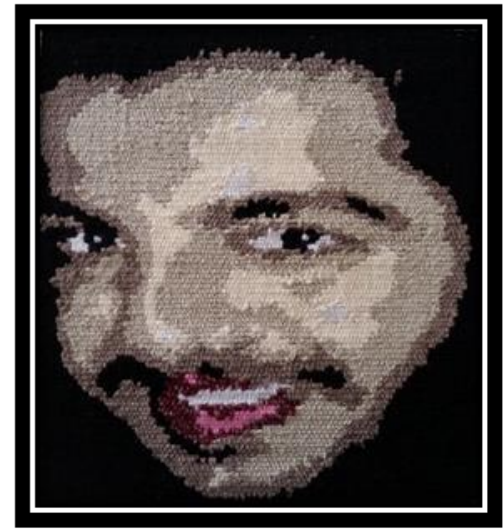

المشغولة (†)

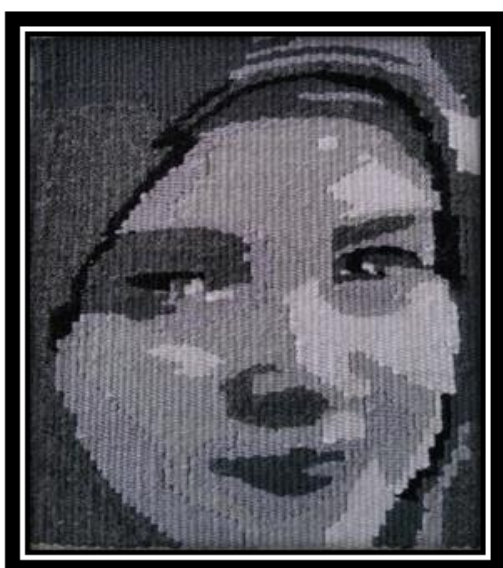

(V) المشغولة

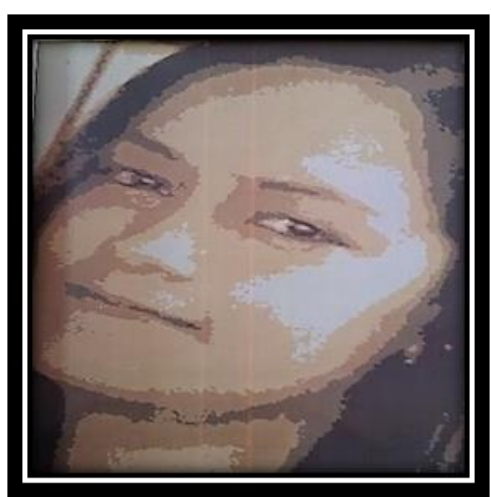

التصميم (؛)

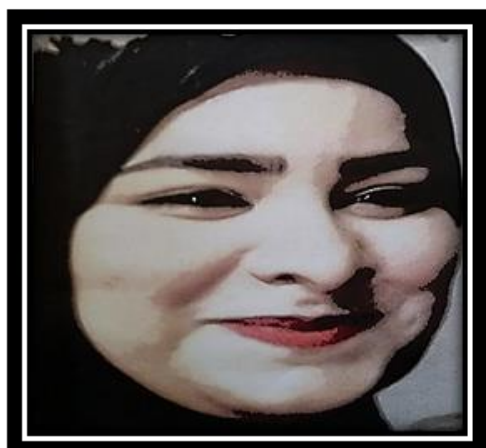

التصميم (0)

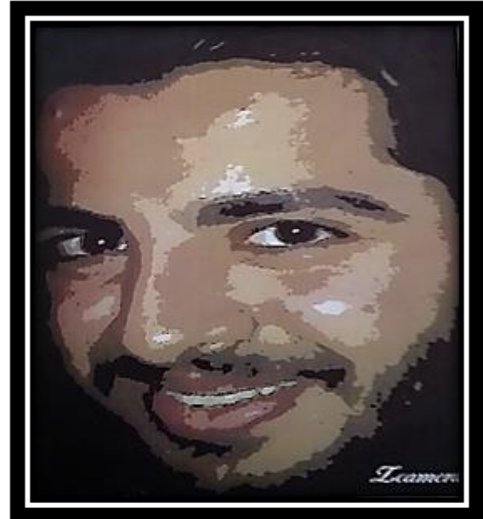

التصميم (1)

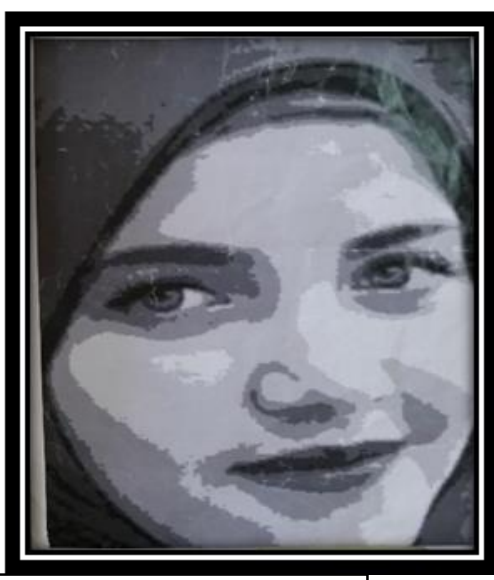

(V) التصميم 

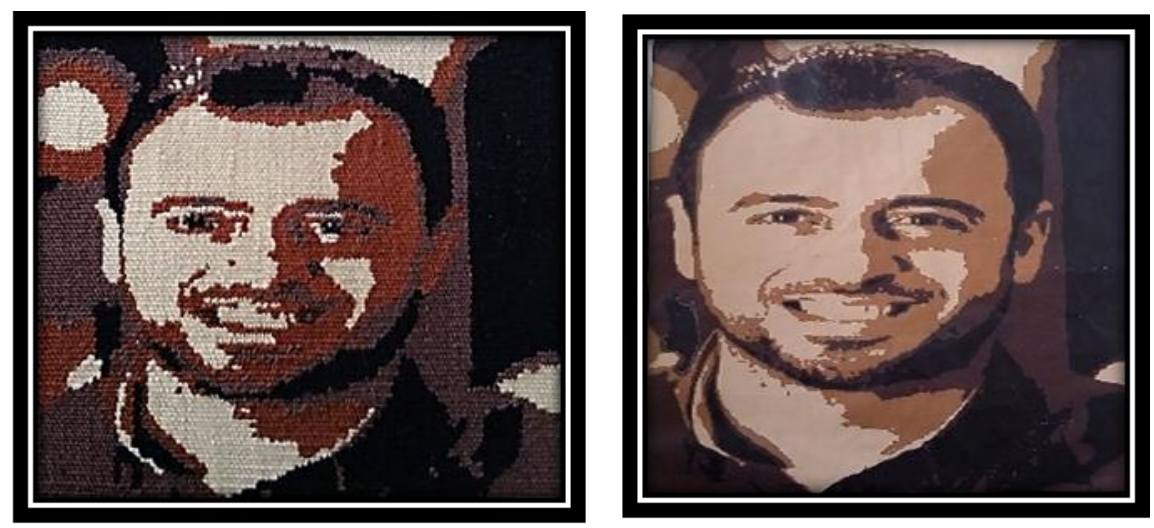

المشغولة (^)

(ㅅ) (التصميم

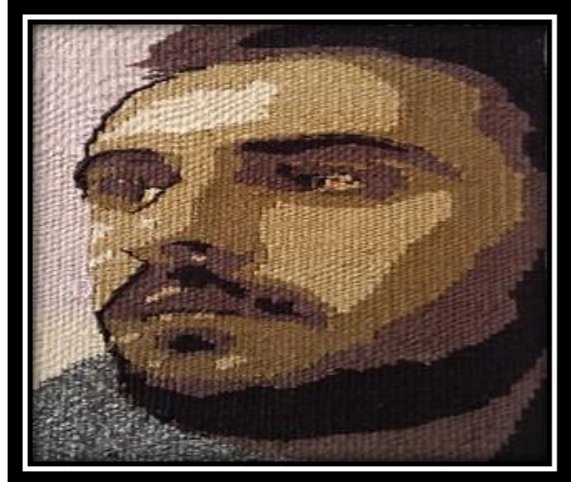

المشغولة (9)

(9) التصميم

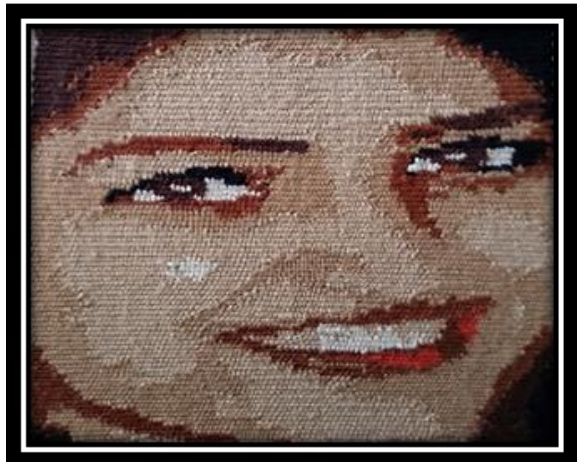

المشغولة (·)
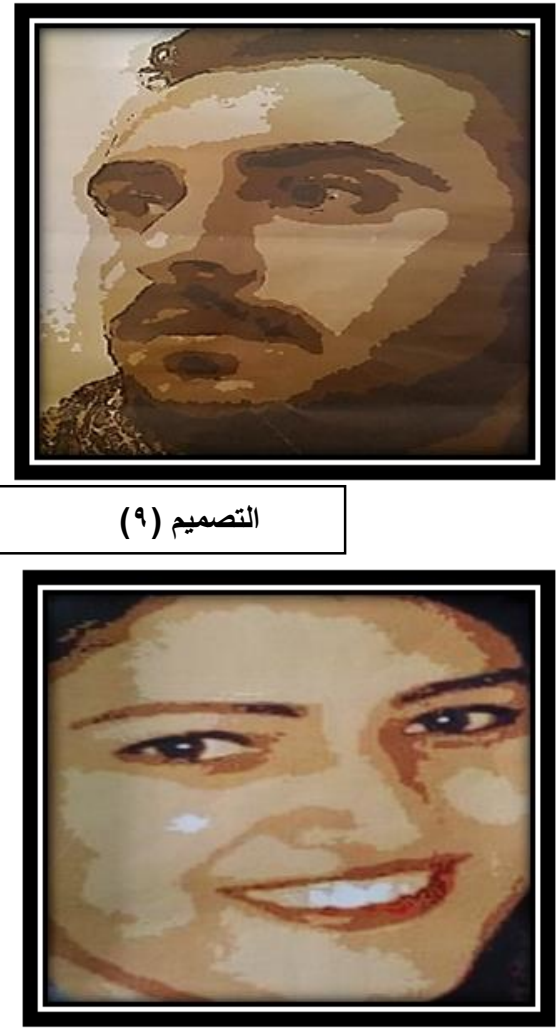

التصميم (·)

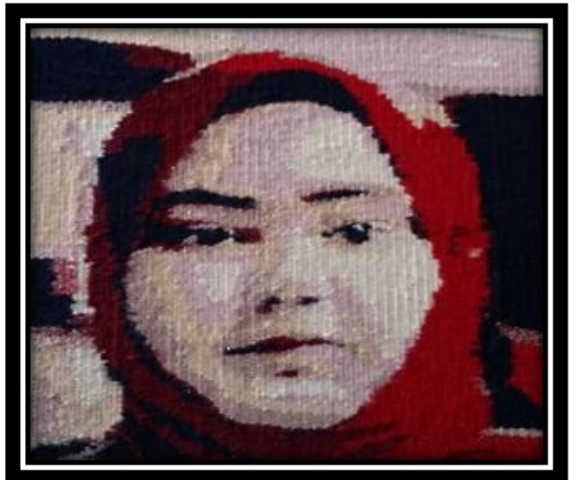

المشغولة (11)

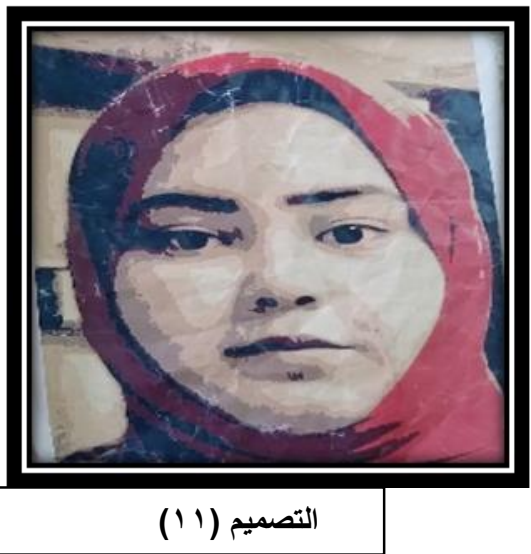



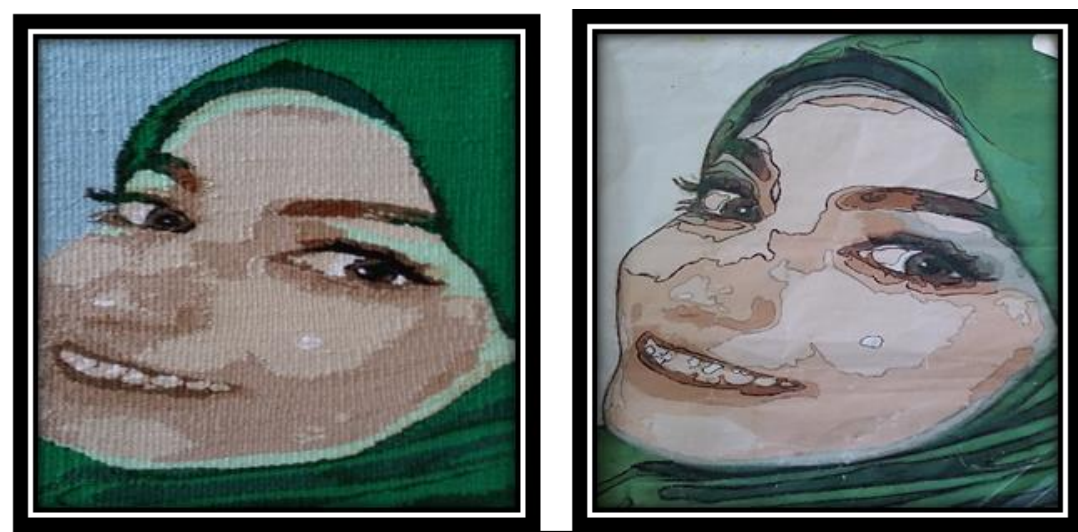

المشغولة (r I )

التصميم (Y I )
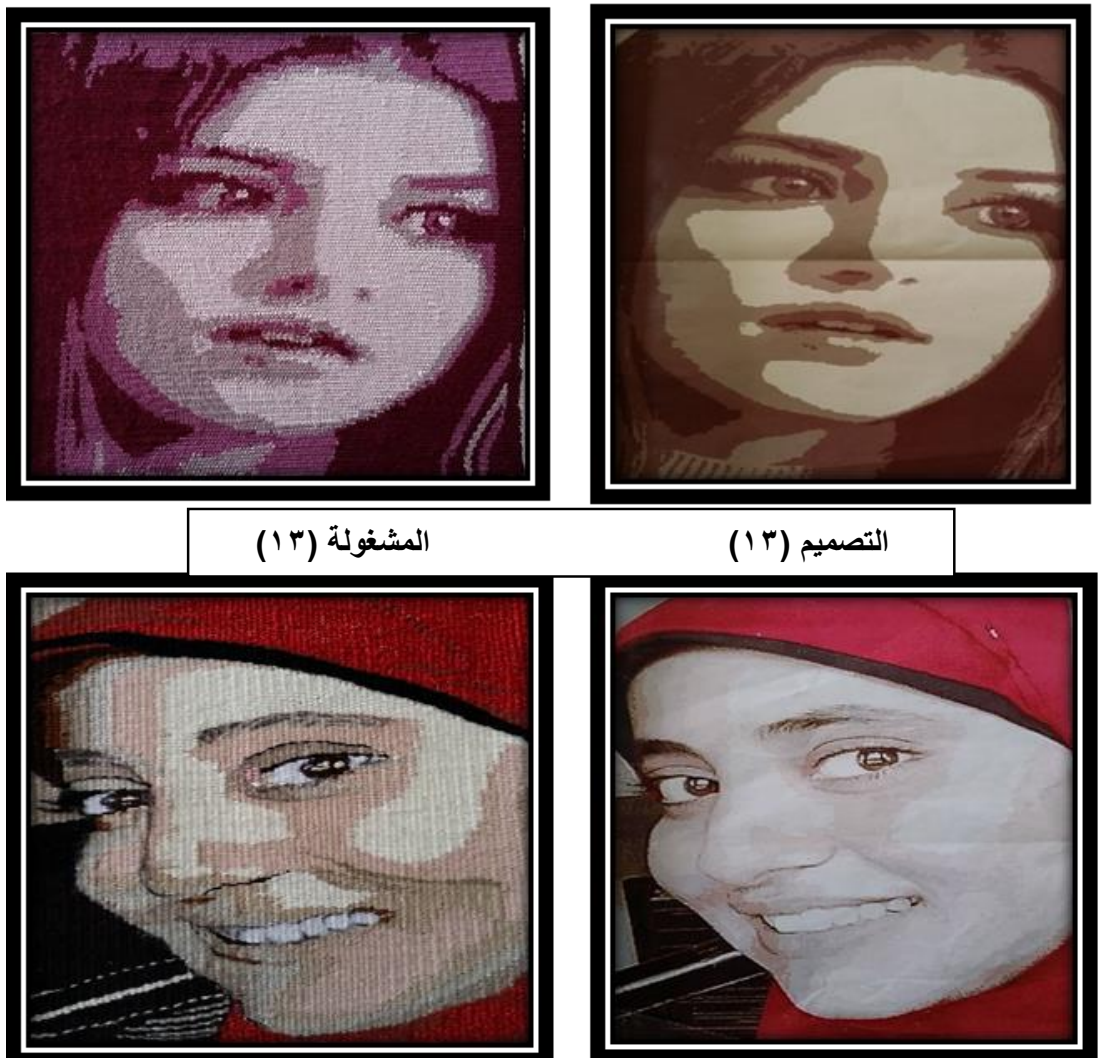

التصميم (T (I)

المشغولة (ع (1)

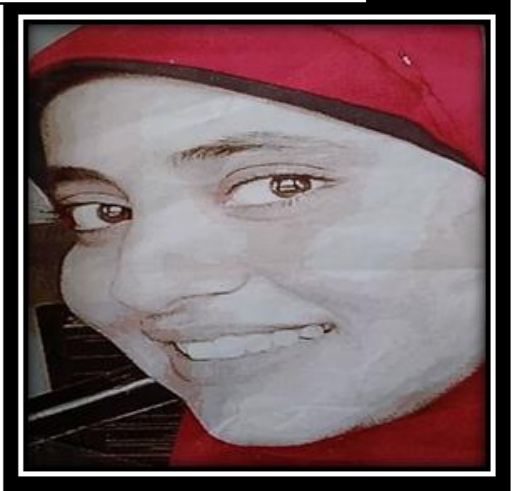

التصميم (؛ ()

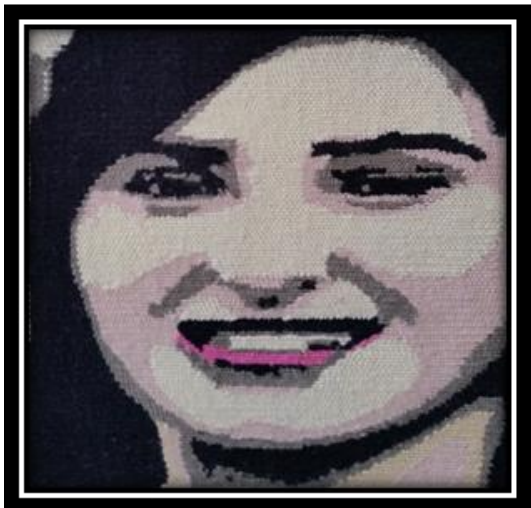

المشغولة (10)

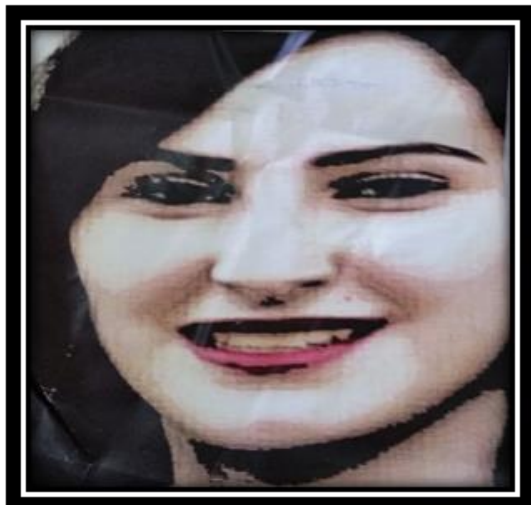

التصميم (10) 


\section{نتائج البحث والتحليل الإحصائي: -}

في ضوء فروض البحث و الدراسات النظرية والتجريبية للبحث يمكن تفسير النتائج الخاصة بالمشغولات النسجية ناتج التجربة الطلابية في ضوء الأسلوب الإحصائي الأتى: اختبار مان_ ويتنى(يو) Mann- Whitney U Test لحساب الفروق بين المجموعتين الضابطة و التجريبية عينة البحث،

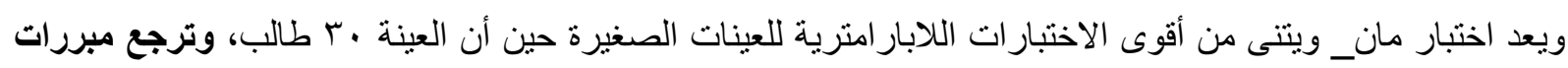

استخدام هذا الإسلوب الإحصائي إلى: - مانى 1- (- صغر عدد عينة البحث. r- إمكانية تحويل درجات التجربة الطلابية ناتج التحكيم إلى رتب. وقامت الباحثة بإعداد استمارة تقييم الشغولات النسجية جدول (1) ناتج التجربة الطلابية، محاولةً لأن تقبس بنوبة الاستمارة الجوانب التشكيلية والفنية والتقنية بالمشغولات النسجية، احتوت الاستمارة على ثلاثة محاور رئيسية يندرج تحت كل محور مجموعة من البنود تعمل على محاولة قياس الجو انب المتعلقة بالمحور. فكان المحور الأول يثير الى: المعالجات التصميمية للصورة الثخصية. والمحور الثانى يشير الى: تو افق الطريقة النسجية مع المعالجات التصميمية للصورة الثخصية. والمحور الثالث يثير الى: الإفادة من الإمكانات التصميمية والتنفيذية لإثر اء المشغولة النسجية. حيث ان تحقق المحاور الثناثة ببنودهم في المشغولات الفنية هو مؤشر لتحقق هدف البحث و إثبات صحة فرئه فروضه. وتم تحديد الدرجات الخاصة بكل بند من البنود المدرجه أسفل كل محور من درجة الي خمسة درجات، وتشير الدرجة المونه الى عدم تحقق البند، وتثير الدرجة ץ الى تحقق البند بدرجه مقبول، وتثنير الدرجة ب الى تحقق البند بتقدير جيد، وتثير

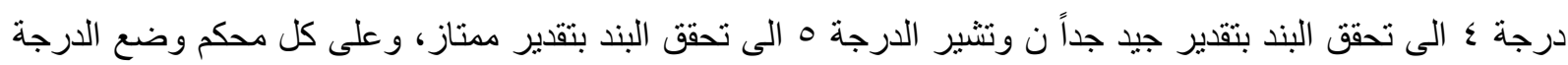
التي يراها لكل بند، وبإحتواء الإستمارة على •ا بنود تكون الدرجة لكل مشغولة (عدد بنود الإستمارة أعلى درجة

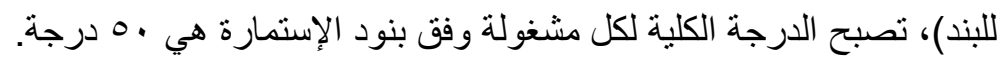

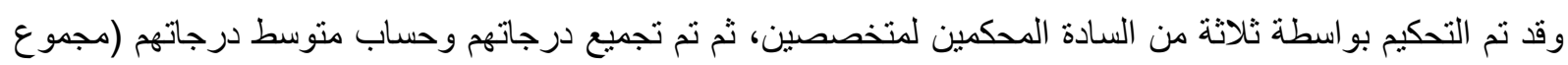
درجات المحكمين لكل مشغولة ؛ عدد المحكمين= متوسط درجات المحكين لكل مشغولة)، للحصول على درجة لكل مشغولة في ضوء تقدير المحكمين الثلاثة، ثم ترتيب درجات أعمال المجموعة التجريبية، ودرجات أعمال المجموعة الضابطة تصاعدياً لحساب رتبة كل درجة وذلك لإجر اء المعالجات الإحصائية وفق إختبار مان - ويتنى (U Test) ، للتحقق من صحة فروض البحث . 
ديسمبر I T T مجلة التراث والتصميم ـ المجلد الاول ـ العدد السادس

جدول رقم (1) يبين إستمارة تقييم المشفولات النسجية ناتج التجربة*.

\begin{tabular}{|c|c|c|c|c|c|c|}
\hline \multicolumn{5}{|c|}{ المشغولة () } & \multirow{2}{*}{ بنود التقييم } & \multirow{2}{*}{ p } \\
\hline 0 & $\varepsilon$ & $r$ & $r$ & 1 & & \\
\hline \multicolumn{7}{|c|}{ أولاً: البند الأول: - } \\
\hline \multicolumn{7}{|c|}{ المعالجات التصميمية للصورة الثخصية. } \\
\hline & & & & & تحقق الإفادة من إمكانات تعديل الصورة الخاصة بكامير ا الهاتف المحمول. & 1 \\
\hline & & & & & وضوح العناصر الأساسية للتصميم خاصةُ ما يتعلق بالخط و المساحة و اللون. & $r$ \\
\hline & & & & & تكاملية الشكل والأرضية بما يعزز نجاح التصميم النسجى للمشغولة. & $r$ \\
\hline & & & & & إنسجام المساحات الخطية و اللونية بالتصميم النسجى للصورة. & $\varepsilon$ \\
\hline & & & & & تو افق المعالجات التقنية للصورة الثخصية مع مواصفات التصميم النسجى & 0 \\
\hline \multicolumn{7}{|c|}{ ثانياً:البند الثانى:- } \\
\hline \multicolumn{7}{|c|}{ تو افق الطريقة النسجية مع المعالجات التصميمية للصورة الثخصية. } \\
\hline & & & & & خلو المشغولة من التفاصيل الزائدة التي تُعيق نجاح التصميم نسجياً & 7 \\
\hline & & & & & تو افق الخامات النسجية المستخدمة مع الطرق الأدائية للتنفيذ. & $\mathrm{V}$ \\
\hline & & & & & نجاح الإسلوب النسجى المستخدم في ترجمة المساحات الخطية و اللونية & $\wedge$ \\
\hline \multicolumn{7}{|c|}{ يُالثاً: البند الثالث: - } \\
\hline \multicolumn{7}{|c|}{ الإفادة من الإمكانات التصميمية والتنفيذية لإثر اء المشغولة النسجية. } \\
\hline & & & & & 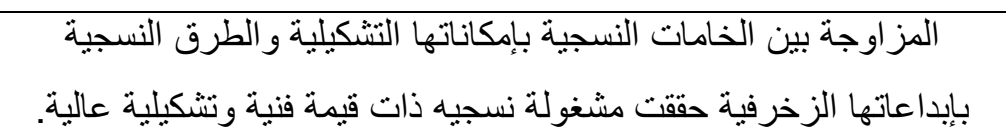 & 9 \\
\hline & & & & & إحتفاظ الصورة الثخصية بهويتها بعد معالجتها تقنياو تنفيذها نسجياً. & $1 \cdot$ \\
\hline
\end{tabular}


جدول (ץ) يبين رتب المجموعتين الضابطة والتجريبية.

\begin{tabular}{|c|c|c|c|c|c|}
\hline الرتبة & دالتجريبة مرتبين الموعتين الضابطة & p & الرتبة & درجات المجموعتين الضابطة & p \\
\hline 17.0 & $\leqslant 0$ & 17 & 1,0 & $1 \leq$ & 1 \\
\hline 17.0 & $\leq 0$ & IV & 1,0 & $1 \varepsilon$ & $r$ \\
\hline $1 \Lambda_{6} 0$ & $\varepsilon V$ & 11 & $\mu_{6} \theta$ & 10 & $r$ \\
\hline $11_{6} 0$ & $\varepsilon V$ & 19 & $\mu_{6} \theta$ & 10 & $\varepsilon$ \\
\hline$r_{1}$ & $\varepsilon \wedge$ & $r \cdot$ & 0 & 17 & 0 \\
\hline$r 1$ & $\leqslant \wedge$ & rI & 7.0 & 11 & 7 \\
\hline$r_{1}$ & $\leqslant \Lambda$ & rr & 7.0 & 11 & V \\
\hline Tr & $\leqslant 9$ & $r r$ & $\Lambda$ & 19 & $\Lambda$ \\
\hline TV & o. & $Y \leqslant$ & 9 & $r$. & 9 \\
\hline$r V$ & o. & ro & 1. & Y I & 1. \\
\hline$r V$ & 0 . & Yq & 11 & ro & 11 \\
\hline$r V$ & 0. & $r V$ & Ir & $r \wedge$ & Ir \\
\hline$r V$ & 0. & $r \wedge$ & $1 \pi$ & rq & $1 \%$ \\
\hline$r V$ & 0. & rq & $1 \varepsilon$ & $r_{1}$ & $1 \leq$ \\
\hline$r V$ & 0 . & $r$. & 10 & rr & 10 \\
\hline
\end{tabular}

جدول (r) يبين نتائج إختبار مان ويتنى لالالة الفروق بين أفراد المجموعتين الضابطة والتجريبية.

\begin{tabular}{|c|c|c|c|c|c|c|}
\hline \multicolumn{2}{|c|}{ قيمة Uالجدولية } & \multirow{2}{*}{ رالضب المجموعة } & \multirow{2}{*}{ رتب التجريبة ر ا } & \multirow{2}{*}{ درجات المجموعة } & \multirow{2}{*}{ درجات المجموعة } & \multirow{2}{*}{ p } \\
\hline $.6 \cdot 1$ & .60 & & & & & \\
\hline \multirow{15}{*}{0,1} & \multirow{15}{*}{$7 ، \varepsilon$} & Ir & $r V$ & $r \wedge$ & 0 . & 1 \\
\hline & & $1 \leqslant$ & TV & $r_{1}$ & 0 . & $r$ \\
\hline & & 7.0 & YI & 11 & $\varepsilon \wedge$ & $r$ \\
\hline & & $1 \pi$ & 19.0 & $r q$ & $\leqslant 0$ & $\varepsilon$ \\
\hline & & 10 & $r r$ & $r r$ & $\leqslant 9$ & 0 \\
\hline & & 0 & $11_{6} 0$ & 17 & $\varepsilon V$ & 9 \\
\hline & & $\Lambda$ & TV & 19 & 0 . & $V$ \\
\hline & & $\mu_{6} 0$ & rI & 10 & $\leqslant \wedge$ & $\Lambda$ \\
\hline & & 7.0 & TV & 11 & 0. & 9 \\
\hline & & 11 & YI & ro & $\leqslant \wedge$ & 1. \\
\hline & & 1. & $1 \Lambda_{6} 0$ & $r_{1}$ & $\varepsilon V$ & 11 \\
\hline & & 1,0 & rV & $1 \varepsilon$ & 0 . & Ir \\
\hline & & 1,0 & $r V$ & $1 \leq$ & 0 . & 14 \\
\hline & & 9 & 19.0 & $r \cdot$ & 20 & 18 \\
\hline & & $T_{6} \theta$ & TV & 10 & 0 . & 10 \\
\hline & & 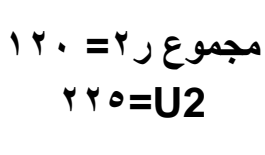 & 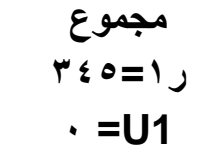 & & & \\
\hline
\end{tabular}




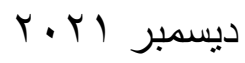

مجلة التراث والتصميم ـ المجلد الاول ـ العدد السادس

$$
\text { U U U (الجدولية) — ب الفروق دالة. }
$$

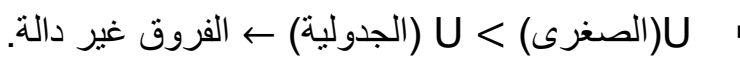$$
\{r \dot{U}+1 \dot{U}=2 U+1 U\} \text { • }
$$$$
\text { ا }
$$

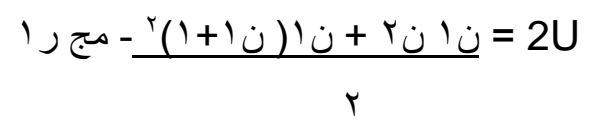$$
\text { ن }
$$

1U

$r \leq 0-\frac{(1+10) 10}{r}+10 \times 10=$ $r \leqslant 0-r \leq 0+r r_{0}=$

صفر $=r \varepsilon 0-1 r \cdot+r r_{0}=1 U$

r

r

$14 \cdot-(1+10) 10+10 \times 10=$ r

$r \cdot-\frac{r \varepsilon}{r}+r r_{0}=$ rYO $=1 r_{0}-I r_{0}+r_{0}=2 U$

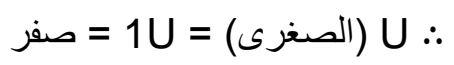

U > $1 U$

ويتضح مما سبق وجود فروق ذات دلالة إحصائية عند مستوى ( ( •، ·) بين رتب درجات أفر اد المجموعة الضابطه ورتب درجات أفراد المجموعة التجرييية، لصالح المجموعة التجريبية وهذا ما يؤكد على إثبات صحة فرض الدراسة (توجد فروق ذات دلالة إحصائية بين المجمو عة الضابطة والمجموعة التجريبية لصالح المجمو عة التجريبية)، و هذا يعنى: أن الأعمال الفنية النسجية للمجموعة التجريية ناتج التجربة الطلابية، حققت وبنسب عالية الإفادة من إمكانات الصورة الثخصية لإثر اء المشغولة النسجية في ضوء بنود إستمارة التحكيم والتي كان القصد منها قياس الجوانب التشكيلية والتقنية و الفنية للمشغولة النسجية. 
تعرف الطلاب على إمكانات للصورة الثخصية وتمكنوا من إجراء المعالجات التصميمية لها بما بتو افق مع التصميم النسجي الناجح و ذلك في ضوء الأتى: اـ الممارسة والتجريب من خلال المعالجات الرقية للصورة الثخصية أناحة الفرصة للوصول الى حلول وصياغات تشكيلية نسجيه ناجحة تترى مجال النسجيات اليدوية. 3- تمكن الطالب من إجر اء معالجات تشكيلية لصورته الثخصية وصياغتها نسجياً بطرقة ناجحة. 4- إكتسب الطالب مهارة المعالجات التصميمية والثقنية والمزج بينهما لصياغة مشغولة نسجيه ثرية بمجموعة من القيم التشكيلية (على مستوى التصميم و الصياغة النسجية). 5- أمكن إستحداث صياغات نسجيه قائمة على القيم التشكيلية و الفنية للصورة الثخصية. 6- ألتزم طلاب المجموعتين التجريبية والضابطه بالوضع الأمامى للصورة الثخصية و أبتعدوا عن الوضع الجانبى أو الثلاث أربع؛ ويرجع ذلك الى إعتماد الطلاب على تصوير أنفسه بالهاتف المحمول على طريقة السيلفى والذي يعزز الوضع الأمامى للصورة. 7- ولعل أهم ما توصل إلية البحث أن الصورة الثخصية مصدر ثرى بالعديد من الإمكانات التشكيلية والقيم الفنية و الجمالية و التي يمكن الإفادة منها في إثر اء النسجيات اليدوية. 8- تم عرض الأعمال الفنية النسجية ناتج التجربة الطلابية في معرض طلابي، بكلية التربية الفنية جامعة المنيا ـ

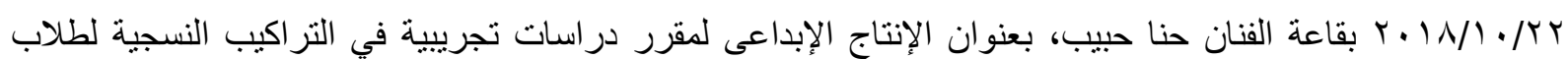

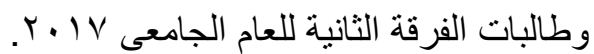

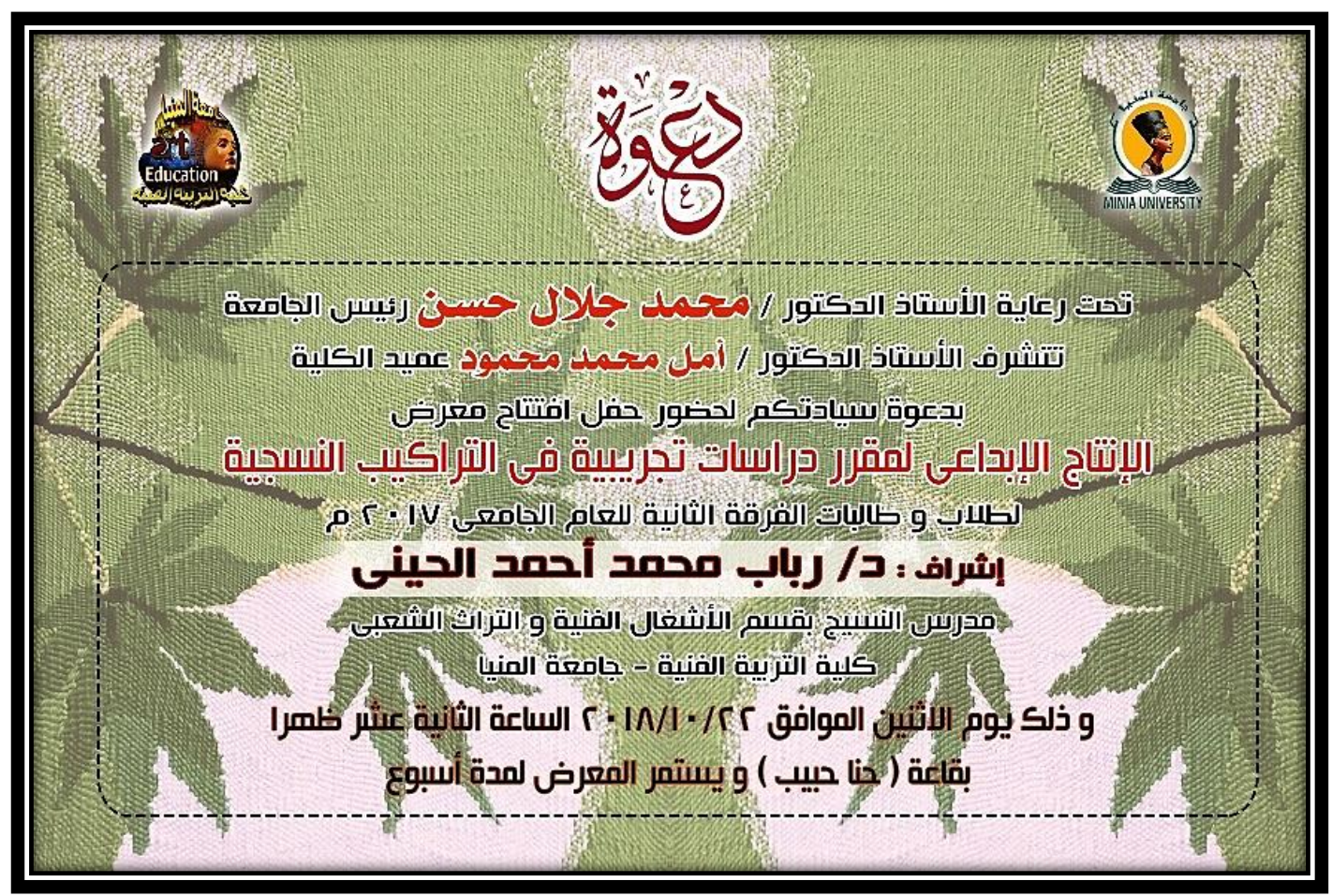


1- ضرورة التعمق في دراسة الإمكانات التكنولوجية والمعالجات الرقمية التي أصبحت مناحة للجميع و إلإفادة من

إمكاناتها في مجال الفنون التشكيلية.

2- الاهتمام بالأبحاث العلمية التي تجمع بين الجانب التشكيلى و التجريبى فى مجال النسيج.

3- إتاحة فرص التجريب المرتبطة بالمشاركة الطلابية من خلال المقررات الدراسية.

4- محاولة البحث عن كل ماهو جديد على مستوى الفكرة، الخامة، التقنية، والإفادة من إمكاناتها التشكيلية لإثراء المشغولة النسجية.

5- الاهتمام بإقامة المعارضة الفنبة الخاصة بالإنتاج الإبداعى للطلاب في مقرر اتهم الدراسية، لتشجيعهم وتحفيز هم على

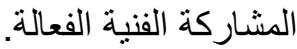
6- تؤكد الباحثة على أهمية طرح مداخل تجريبية متنو عة على طلاب كلية التربية الفنية لإثراء العملية التعليمية و إثارة العملية الإبداعية لديهر.

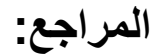

1- أحمد، خالد جلال الدين حماد،" الصورة الثخصية الذاتية بين الرمز والدالالة التعبيرية: دراسة تاريخية تحليلية، رسالة

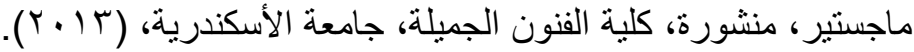
'ahmad , khalid jalal aldiyn hamaad ," alsuwrat alshakhsiat aldhaatiat bayn alramz waldalalat altaebiriat : dirasat tarikhiat tahliliat, risalat majistir , manshurat, kuliyat alfunun aljamilat, jamieat al'uskandariat, (2013) .

2- الجوهرى، دعاء منصور أبو المعاطى محمد،" القيم التشكيلية والتعبيرية للبورتريه كمنطلق لإستحداث صياغات

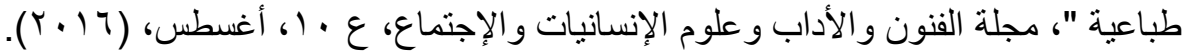
aljawharaa , duea' mansur 'abu almueataa muhamad ," alqiam altashkiliat waltaebiriat lilburtrih kamuntalaq li'iistihdath siaghat tibaeia ", majalat alfunun wal'adab waeulum al'iinsaniaat wal'iijtimae, e 10, 'aghustus ,(2016) .

3- المرغلانى، فوزية عبد العزيز عمر،" القيم الدلالية للصورة الشخصية كمدخل لتصميم مجسمات معدنية"، المجلة

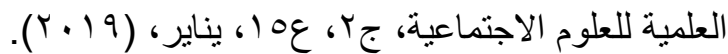
almirghalanaa, fawziat eabd aleaziz eumri," alqiam aldilaliat lilsuwrat alshakhsiat kamadkhal litasmim mujasamat maediniatin", almajalat aleilmiat lileulum aliajtimaeiati, ja2, ea15, yanayir , (2019)

$$
\text { 4- أمهز ، محمود، " التبار ات الفنية المعاصرة “، شركة المطبو عات للتوزيع و النشر، (990 (1) ). }
$$
'amhaza, mahmud, " altayaarat alfaniyat almueasira " , sharikat almatbueat liltawzie walnashri, (1995).

5- سيد، منار حسين عبد الفتاح، " الاتجاهات المعاصرة للنسجيات اليدوية كمدخل لإستحداث تذكار ات سياحية نسجيه "،

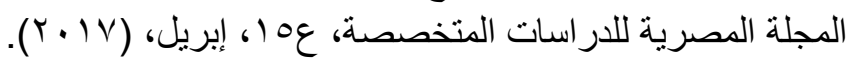

sid, manar husayn eabd alfataahi, " alaitijahat almueasirat lilnusjiaat alyadawiat kamadkhal li'iistihdath tadhkarat siahiat nusjih ", almajalat almisriat lildirasat almutakhasisati, ea15, 'iibril, (2017).

6- شاكر، سهام عبد العزيز حامد، " الأبعاد التشكيلية و المفاهيمية لفن البورتريه المعاصر كمدخل لتأكيد الهوية الثقافية “،

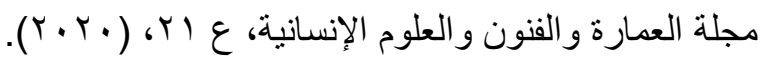
shakir , siham eabd aleaziz hamid, " al'abead altashkiliat walmafahimiat lifani alburtirih almueasir kamadkhal litakid alhuiat althaqafia " , majalat aleimarat walfunun waleulum al'iinsaniat, e 21,(2020) 
7- عبد العزيز، سهام حامد،" الأبعاد التشكيلية والمفاهيمية لفن البورنريه المعاصر كمدخل لتأكبد الهوية التقافية “، مجلة

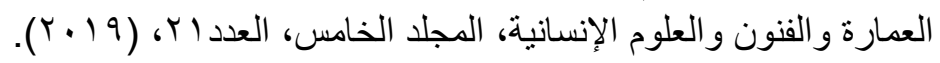
eabd aleaziza, siham hamid ," al'abead altashkiliat walmafahimiat lifani alburtirih almueasir kamadkhal litakid alhuiat althaqafia " ,majalat aleimarat walfunun waleulum al'iinsaniat , almujalad alkhamis , aleudadi21 , (2019)

8- عبد المجيد، سمية، " المتغيرات التشكيلية في الأعمال النسجية المصرية المعاصرة "، المجلة العلمية لجمعية إمسيا

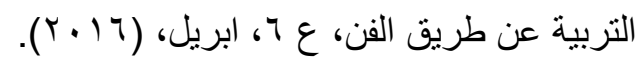
eabd almajid , sumyat, " almutaghayirat altashkiliat fi al'aemal alnasjiat almisriat almueasira ", almajalat aleilmiat lijameiat 'iimsia altarbiat ean tariq alfani , e 6 , abril , (2016).

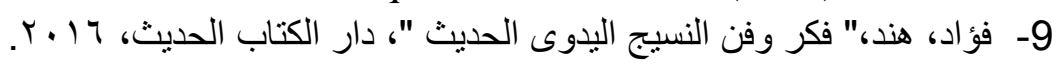

fuaadi, hindi," fakar wafanu alnasij alyadwaa alhadith ", dar alkitab alhadith , 2016.

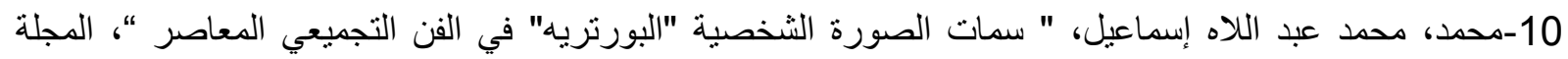

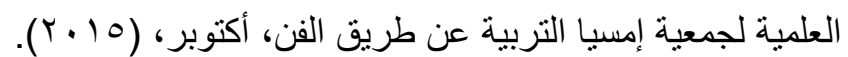
muhamad , muhamad eabd allaah 'iismaeil , " simat alsuwrat alshakhsia "alburtrih" fi alfani altajmieii almueasir " , almajalat aleilmiat lijameiat 'iimsia altarbiat ean tariq alfani , 'uktubar, (2015).

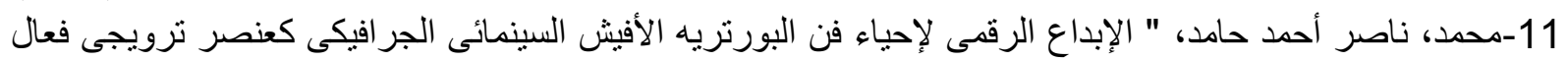

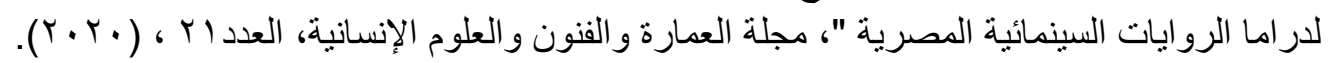
muhamadu, nasir 'ahmad hamid, " al'iibdae alraqmaa li'iihya' fani alburtirih al'afish alsiynamayaa aljiraafikaa kaeunsur tarwijaa faeaal lidirama alriwayat alsiynamayiyat almisria ", majalat aleimarat walfunun waleulum al'iinsaniat ,aleadad21 , (2020).

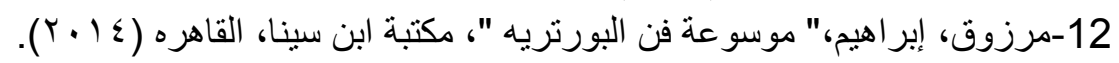
marazuq, 'iibrahim ," mawsueat fani alburtirih ", maktabat abn sina , alqahirah (2014)

$$
\text { 13-مصطفى، إبر اهيم،"مجمع اللغه العربيه"، الجزء الأول، القاهرة، (1970 (1970). }
$$

mustafaa ،'iibrahim ,"majamae allughah alearabiihi" , aljuz' al'awal , alqahirat , (1965) 14-مقلد، بلال أحمد إبراهيم،" تطويع الصياغات الفنية للعناصر الحية في المنسوجات القبطية لتلائم إسلوب الطباعة

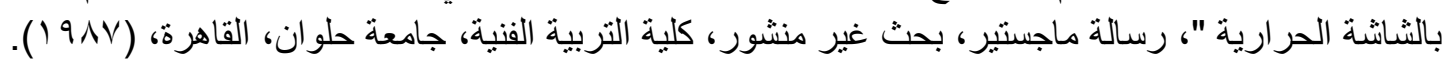
miqalad , bilal 'ahmad 'iibrahim ," tatwie alsiyaghat alfaniyat lileanasir alhayat fi almansujat alqibtiat lituliayim 'iislub altibaeat bialshaashat alhararia ", risalat majistir, bahth ghayr manshur, kuliyat altarbiat alfaniyat, jamieat hulwan , alqahirat , ,(1987).

15- عفيفي, أيمن أحمد. " جماليات الزخارف المنقوشة علي أبو اب مدينة الهجرين الأثرية باليمن كمدخل لإثراء المشغولة

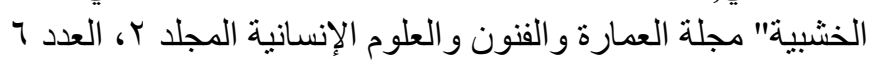

15- eafifi, 'ayman 'ahmad. "jamaliaat alzakharif almanqushat eali 'abwab madinat alhijrin al'athariat bialyaman kmadkhal li'iithra' almashghulat alkhashabiati" majalat aleimarat walfunun waleulum al'iinsaniat almujalad 2 , aleadad 6

15- https://www.researchgate.net/publication/340656047_The_Picasso\%27s_portrait_as_a_so urce to treach the hanging textile_on the art_education_department $\% 27 \mathrm{~s}$ s_students_at the faculty_of_Women_Haramoot_University_fn_albwrtryh_nd_bykasw_kmsdr_lathra_almlqat alnsj

available until 3-7-2021

16- https://www.google.com/search?q=\%D8\%A8\%D9\%88\%D8\%B1\%D8\%AA\%D8\%B1\%D 9\%8A\%D8\%A9+\%D9\%85\%D9\%86\%D8\%B3\%D9\%88\%D8\%AC\&tbm=isch\&chips=q:\%D 8\%A8\%D9\%88\%D8\%B1\%D8\%AA\%D8\%B1\%D9\%8A\%D8\%A9+\%D9\%85\%D9\%86\%D8 \%B3\%D9\%88\%D8\%AC,online chips:\%D8\%A8\%D9\%88\%D8\%B1\%D8\%AA\%D8\%B1\%D 


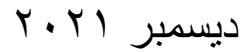

مجلة التراث والتصميم ـ المجلد الاول ـ العدد السادس

9\%8A\%D9\%87\%D8\%A7\%D8\%AA:yTunXONqnJQ\%3D\&hl=ar\&sa=X\&ved=2ahUKEwiG nP7Wk-

vxAhWQAmMBHQWkDSEQ41YoB3oECAEQHQ\&biw=1263\&bih=689\#imgrc=NEbXknL W_KtsqM available until 17-7 -2021

17-https://www.pinterest.com/pin/374854368962355816/

18- https://www.google.com/search?q=\%D8\%A8\%D9\%88\%D8\%B1\%D8\%AA\%D8\%B1\%D 9\%8A\%D8\%A9+\%D9\%85\%D9\%86\%D8\%B3\%D9\%88\%D8\%AC\&tbm=isch\&hl=ar\&chips =q:\%D8\%A8\%D9\%88\%D8\%B1\%D8\%AA\%D8\%B1\%D9\%8A\%D8\%A9+\%D9\%85\%D9\%8 6\%D8\%B3\%D9\%88\%D8\%AC,online chips:\%D8\%A8\%D9\%88\%D8\%B1\%D8\%AA\%D8\% B1\%D9\%8A\%D9\%87\%D8\%A7\%D8\%AA:yTunXONqnJQ\%3D,online chips:\%D9\%81\%D 9\%86:H4OKRZfQoNE\%3D\&sa=X\&ved=2ahUKEwi6vcvnk-

vxAhUG0eAKHRuqBSQQ41YoBXoECAEQHA\&biw=1263\&bih=632\#imgrc=0aDQ10WKg $\underline{\mathrm{x} \_\mathrm{GoM}}$

19- https://www.facebook.com/VelonesInAction/photos/pcb.1025053741568370/1025052628 $\underline{235148}$

20- https://www.pinterest.com/pin/519743613223117238

21- https://www.pinterest.com/pin/332140541269839636/

22- https://www.pinterest.com/pin/294282156874403058/

23- https://www.pinterest.com/pin/220465344230609631/

24- https://www.pinterest.com/pin/156640893276641407/

25-https://www.pinterest.com/pin/156640893276641407/ 